\title{
Ultra-High Resolution Steady-State Micro- Thermometry Using a Bipolar Direct Current Reversal Technique
}

Jason Y. Wu

yingzhi.wu@uconn.edu

\section{Recommended Citation}

Wu, Jason Y., "Ultra-High Resolution Steady-State Micro-Thermometry Using a Bipolar Direct Current Reversal Technique" (2016). Master's Theses. 988.

https://opencommons.uconn.edu/gs_theses/988 
Ultra-High Resolution Steady-State Micro-Thermometry Using a Bipolar Direct Current Reversal Technique

by

Jason Yingzhi Wu

B.S., University of Connecticut, 2015

\author{
A Thesis \\ Submitted in Partial Fulfillment of the \\ Requirements for the Degree of \\ Master of Science \\ at the \\ University of Connecticut
}

2016 
Copyright by

Jason Yingzhi Wu

2016 
Master of Science Thesis.

Ultra-High Resolution Steady-State Micro-Thermometry Using a Bipolar Direct Current

Reversal Technique

Presented by

Jason Yingzhi Wu, B.S.

Major Advisor

Michael Thompson Pettes

Associate Advisor

Ugur Pasaogullari

Associate Advisor

Boris Sinkovic

University of Connecticut

2016

iii 


\section{Acknowledgments}

I would not be able to make these achievements without the mentorship of my advisor, Prof. Michael Pettes, who has led me into the field of nanoscale heat transfer, I have been able to develop intellectually in this research field with his encouragement and inspiration. I am also thankful to my fellow lab member, Wei $\mathrm{Wu}$, whose discussions and technical experiences have been helping me in this interdisciplinary research field. Additionally, I would like to thank the faculty and staff of the Institute of Materials Science at the University of Connecticut for providing the specialized facilities and discussions to complete this research.

I would like to thank two funding agencies, NSF and Board of Education and Services for the Blind, for the support of finances to complete this experimental study. Particularly, Board of Education and Services for Blind allows me to achieve my master’s degree in engineering freely and the National Science Foundation Graduate Research Fellowship Program offers me the freedom to broaden the scope of my dissertation research.

Finally, I would not have been able to complete this study without the moral support and understanding of my family. I am deeply appreciative of their encouragement to pursue these achievements. 


\section{Table of contents}

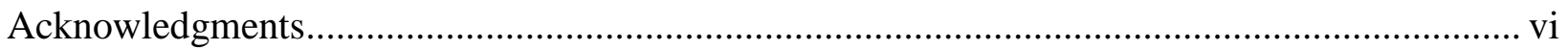

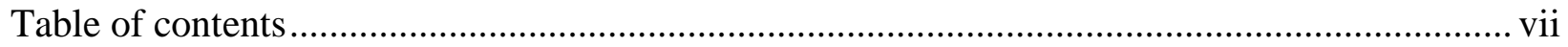

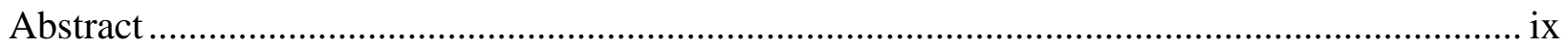

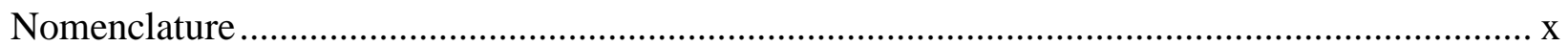

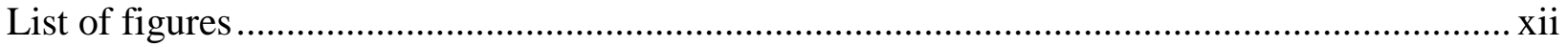

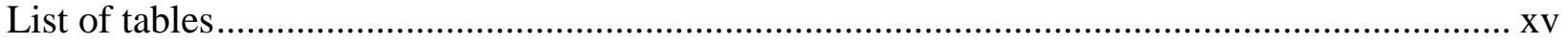

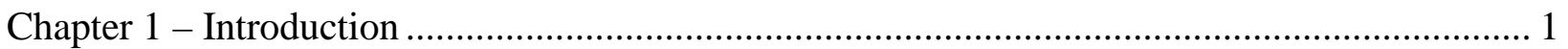

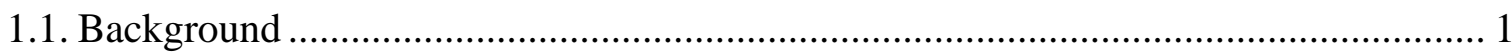

1.2. Suspended micro-thermometry measurement .................................................... 1

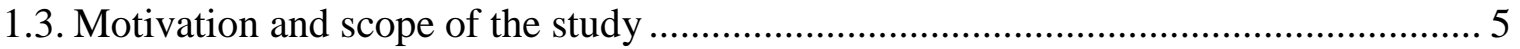

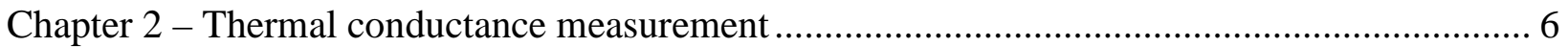

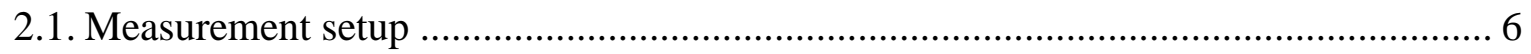

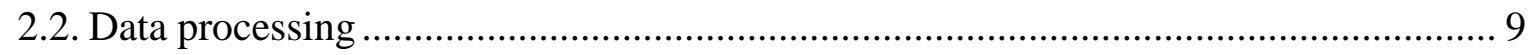

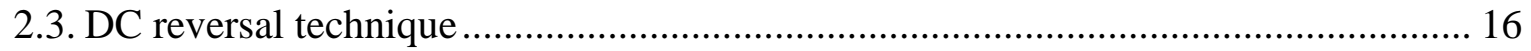

Chapter 3 - Temperature and background thermal conductance resolution.............................. 19

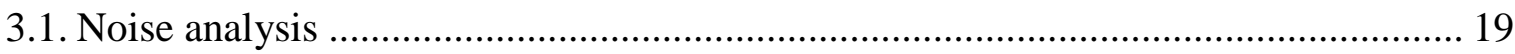

3.2. Temperature resolution ............................................................................... 24

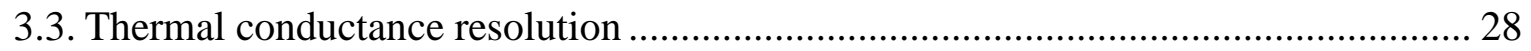

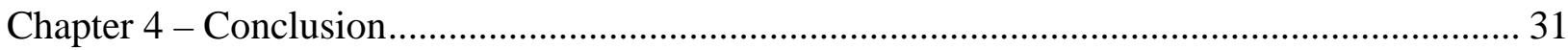




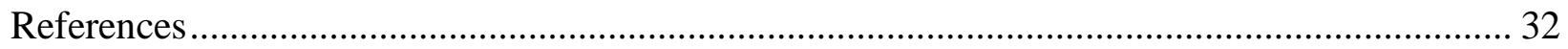




\begin{abstract}
The suspended micro-thermometry technique is one of the most prominent methods for probing the in-plane thermal conductance of low dimensional materials (nanowires, nanotubes, and nanoplates), where a suspended mircrodevice containing two built-in platinum resistors that serve as both heater and thermometer is used to measure the temperature and heat flow across the sample. In previous lock-in-based measurement schemes, the thermal conductance resolution of this method is on the order of $1 \mathrm{nW} / \mathrm{K}$. The presence temperature fluctuations in the sample chamber, background thermal conductance through the device, residual gases, and radiation are significant sources of error when the sample thermal conductance is comparable or smaller than the background thermal conductance, on the order of $300 \mathrm{pW} / \mathrm{K}$ at room temperature.
\end{abstract}

In this thesis, a high resolution and high throughput thermal conductance measurement scheme is presented in which a bipolar direct current reversal technique is adopted to replace the lock-in technique. This scheme benefits from a bipolar direct current (DC) reversal measurement which is a well-established technique to remove offset and low frequency noises during measurement, and involves less instrumentation and simple data analysis. This modern DC reversal technique exhibits less than one half the amount of white noise and an order of magnitude lower $1 /$ f noise than the most commonly used lock-in amplifiers. Over a temperature range of 30$375 \mathrm{~K}$, we demonstrate a temperature resolution of $0.97-2.62 \mathrm{mK}$ and a thermal conductance resolution of $2-26 \mathrm{pW} / \mathrm{K}$. The background conductance of the suspended microdevice is determined accurately by this method and allows for straightforward isolation of this source of error. This simple and high-throughput measurement technique will allow for more accurate and effective investigation of fundamental phonon transport mechanisms in individual nanomaterials. 


\section{Nomenclature}

$f_{\mathrm{h}}=$ AC excitation frequency of heating PRT $(\mathrm{Hz})$

$f_{\mathrm{s}}=$ AC excitation frequency of sensing PRT $(\mathrm{Hz})$

$G_{\mathrm{b}}=$ thermal conductance of the 6 beams supporting each membrane $(\mathrm{W} / \mathrm{K})$

$G_{\mathrm{bg}}=$ background thermal conductance $(\mathrm{W} / \mathrm{K})$

$G_{\mathrm{s}}=$ sample thermal conductance $(\mathrm{W} / \mathrm{K})$

$i_{\mathrm{ac}}=\mathrm{AC}$ sensing current $(\mathrm{A})$

$I_{\mathrm{dc}}=$ DC current passing through the heating PRT (A)

$k_{\mathrm{B}}=$ Boltzmann constant $(\mathrm{J} / \mathrm{K})$

$\mathrm{NEG}=$ noise equivalent thermal conductance $(\mathrm{W} / \mathrm{K})$

$\mathrm{NET}_{\text {Johnson }}=$ noise equivalent temperature arising from Johnson noise (K)

$\mathrm{NET}_{\mathrm{s}}=$ noise equivalent temperature of sensing membrane PRT (K)

$\mathrm{NET}_{\text {temperature drift }}=$ noise equivalent temperature arising from temperature drift $(\mathrm{K})$

$P=$ pressure (bar)

$Q_{1}=$ heat dissipated from heating membrane to silicon chip (W)

$Q_{\mathrm{ac}+\mathrm{dc}}=\mathrm{AC}+\mathrm{DC}$ Joule heat generated on the heating membrane (W)

$Q_{\mathrm{h}}=$ Joule heat generated on the heating membrane (W)

$Q_{\mathrm{L}}=$ Joule heat generated on each Pt lead (W)

$Q_{s}=$ heat transfer from heating membrane to sensing membrane (W)

$R_{\mathrm{b}}=G_{\mathrm{b}}{ }^{-1}=$ thermal resistance of the 6 beams supporting each membrane $(\mathrm{K} / \mathrm{W})$

$R_{\mathrm{h}}=$ electrical resistance of the heating membrane $\operatorname{PRT}(\Omega)$

$R_{\mathrm{L}}=$ electrical resistance of each Pt lead $(\Omega)$

$R_{\mathrm{S}}=$ electrical resistance of the sensing membrane $\operatorname{PRT}(\Omega)$ 
$t=$ time $(\mathrm{s})$

$T_{0}=$ sample mount temperature $(\mathrm{K})$

$T_{\mathrm{avg}}=$ average temperature $(\mathrm{K})$

$T_{\mathrm{h}}=$ temperature on the heating membrane $(\mathrm{K})$

$T_{\mathrm{s}}=$ temperature on the sensing membrane $(\mathrm{K})$

$V_{1,2,3 \text { or final }}=$ voltage response of the PRTs during DC reversal measurement $(\mathrm{V})$

$\Delta f=$ noise equivalent bandwidth $(\mathrm{Hz})$

$\Delta R_{\mathrm{h}}=$ electrical resistance rise on the heating membrane $(\mathrm{K})$

$\Delta R_{\mathrm{S}}=$ electrical resistance rise on the sensing membrane $(\mathrm{K})$

$\Delta T_{\mathrm{h}}=$ temperature rise on the heating membrane $(\mathrm{K})$

$\Delta T_{\mathrm{s}}=$ temperature rise on the sensing membrane $(\mathrm{K})$

$\Delta V_{\text {electrical }}=$ electrical noise arising from the total intrinsic noise of resistance (V)

$\Delta V_{\text {Johnson }}=$ electrical noise arising from the Johnson noise of resistance $(\mathrm{V})$

$\Delta V_{\text {noise }}=$ total voltage noise in the electrical resistance measurement $(\mathrm{V})$

$\Delta V_{\text {temperature drift }}=$ electrical noise arising from the ambient temperature drift (V)

$\alpha_{\mathrm{h}, \mathrm{s}}=$ temperature coefficient of resistance of the heating and sensing PRTs $\left(\mathrm{K}^{-1}\right)$

$\kappa_{\text {air }}=$ thermal conductivity of residual air molecules $[\mathrm{W} /(\mathrm{m} \cdot \mathrm{K})]$

$\sigma=$ standard derivation of the measured resistance $(\Omega)$

$\sigma_{\mathrm{G} g}=$ standard derivation of the measured background thermal conductance $(\mathrm{W} / \mathrm{K})$

$\sigma_{\text {temp }}=$ Overall (pooled) standard derivation of the measured sensing temperature (K)

$\tau=$ thermal time constant of the suspended microdevice (s)

$\zeta=$ numerical factor correlating resistance rise with temperature rise on heating membrane 


\section{List of figures}

Figure 1.1. Suspended micro-thermometry measurement schemes. (a) Electrical and thermal circuits of the suspended micro-thermometry device with unmodulated heating current and modulated sensing current (reproduced from Ref. 3). (b) Electrical circuit of the suspended micro-thermometry device adapted by a differential measurement scheme. The matching device allows this technique to isolate the background thermal conductance during the measurement (reproduced from Ref. 36), (c) A modified suspended micro-thermometry device adapted by a Wheatstone bridge scheme with modulated heating current and unmodulated sensing current (reproduced from Ref. 38). The Wheatstone bridge circuit is used to eliminate the temperature drift from the sample chamber. (d) A single-pad suspended micro-thermometry device with two PRTs on the suspended membrane adapted by a differential scheme with modulated heating current and unmodulated sensing current (reproduced from Ref. 37). The matching resistor is used to eliminate the temperature drift from the sample chamber.

Figure 2.1. Schematic of the suspended microdevice and circuit diagram of the DC reversal technique to measure the electrical resistances of the heating and sensing PRTs on a suspended microdevice. Shown below is the corresponding thermal circuit. A $10 \mathrm{M} \Omega$ ultra high precision resistor is used to convert the voltage source into a DC current source. A high input impedance $\left(10^{14} \Omega\right)$ programmable current source and high input impedance nanovoltmeter $\left(>10^{12} \Omega\right.$ ) are connected to obtain the 4-probe differential voltage on each PRT.

Figure 2.2. Kinetic theory calculation of the thermal conductivity of residual air molecules, $\kappa_{\text {air }}$, inside an enclosure chamber with a diameter of 2.5 inches ( sample chamber diameter) as a function of pressure, $P$, from $10^{-10}$ to 1000 mbar at certain ambient chamber temperature $(T=4,150$, and $300 \mathrm{~K})$ by kinetic theory of gases. inset shows corresponded air thermal conductivity within cryostat chamber pressure range $\left(10^{-10}\right.$ to $10^{-8}$ mbar).

Figure 2.3. (a) Ultra high vacuum cryostat chamber pressure as a function of temperature recorded at the sample mount, $T_{0}$ over a temperature range from 4 to $300 \mathrm{~K}$. (b) Measured cryostat chamber pressure as a function of time at $4 \mathrm{~K}$ sample mount temperature, the system maintained vacuum better than $8.5 \times 10^{-10}$ mbar over 24 hours. (c) Measured cryostat sample mount temperature as a function of time at $4 \mathrm{~K}$, it maintained a stability better than $1 \mathrm{mK}$ over 24 hours. (d) Measured cryostat chamber pressure as a function of time at $375 \mathrm{~K}$ sample mount temperature, it maintained vacuum better than $1.5 \times 10^{-8}$ mbar over 24 hours. (e) Measured cryostat sample mount temperature as a function of time at $375 \mathrm{~K}$, it maintained a stability better than $20 \mathrm{mK}$ over 24 hours. Data depicted in (b) and (c) were collected while the temperature of the heater was set at $4.0000 \mathrm{~K},(\mathrm{e})$ and $(f)$ were collected while the temperature of heater was set at $375.000 \mathrm{~K}$. The temperature drift in the thermal conductance measurement was much smaller than above data because each measurement set was taken within 0.5 hours. 
Figure 2.4. Electrical resistance, $R$, and temperature coefficient of resistance (TCR), $\alpha$, of the heating and sensing PRTs as a function of temperature recorded at the sample mount, $T_{0}$. (a) Measured heating and sensing PRT electrical resistances, $R_{h}$ and $R_{s}$ respectively, over a temperature range from 4 to $375 \mathrm{~K}$ and (b) the corresponding TCR of heating and sensing PRTs, $\alpha_{\mathrm{h}}$ and $\alpha_{\mathrm{s}}$ respectively. The TCR at each temperature point is calculated over 15 measured resistance points which corresponds to a local temperature range of approxiately $T_{0} \pm 3 \mathrm{~K}$.

Figure 2.5. Normalized first harmonic component of the measured resistance rise of the heating PRT as a function of the frequency of AC current coupled to the DC heating current for different AC waveforms at $290 \mathrm{~K}$. The value of $\zeta$ in Eq.4 can be determined by the following relationship, $\zeta=3 \Delta R_{h}\left(f_{h}\right) / \Delta R_{h}\left(f_{h}=1 \mathrm{~Hz}\right)$. Note, the DC heating current here was provided by a Keithley 6221.

Figure 2.6. Normalized first harmonic component of the measured resistance rise of the heating PRT as a function of the frequency of AC current coupled to the DC heating with a lockin technique, measured using a Keithley 6221 DC current source and a Keithley 6517B electrometer with a $10 \mathrm{M} \Omega$ precision resistor at $290 \mathrm{~K}$. The value of $\zeta$ in Eq. 4 can be determined by the following relationship, $\zeta=3 \Delta R_{h}\left(f_{h}\right) / \Delta R_{h}\left(f_{h}=1 \mathrm{~Hz}\right)$.

Figure 2.7. Normalized first harmonic component of the measured resistance rise of the heating PRT as a function of the frequency of AC current coupled to the DC heating current at 375, 290, and 75 K obtained by the DC reversal technique and by the lock-in technique with square wave excitation. The value of $\zeta$ in Eq.4 can be determined by following relationship, $\zeta=3 \Delta R_{h}\left(f_{h}\right) / \Delta R_{h}\left(f_{h}=1 \mathrm{~Hz}\right)$. Note, the DC heating current was provided by a Keithley 6221 when the lock-in technique was used.

Figure 2.8. Schematic of the Keithley 6221 current source and Keithley 2182A nanovoltmeter DC reversal measurement technique (Delta Mode) data processing. The time period is not shown to scale.

Figure 3.1. Rise in measured resistance of the PRT caused by self-heating from the AC sensing current, $\Delta R\left(i_{a c}\right)=R\left(i_{a c}\right)-R\left(i_{a c}=0.3 \mu \mathrm{A}\right)$, as a function of $A C$ sensing current amplitude at $22.37 \mathrm{~Hz}$. The measured standard derivation of the resistance, $\sigma / R\left(i_{a c}\right)$, is shown for comparison in units of parts per million. An optimal $i_{a c}$ of $1.5 \mu$ A peak-to-peak is used for the DC reversal technique based on minimizing noise while maintaining an acceptably small resistance rise corresponding to $71.6 \mathrm{mK}$.

Figure 3.2. Measured sensing PRT temperature rise as a function of $Q_{h}=I_{d c}{ }^{2} R_{h}$, shown for varied AC excitation current $(f=22.37 \mathrm{~Hz})$ of $0.5,1.5,2.5$, and $3.5 \mu \mathrm{A}$ and obtained at $T_{0}=$ $375 \mathrm{~K}$. The inset shows the low $Q_{h}$ regime, note that $1.5 \mathrm{uA}$ is sufficient to achieve high resolution without inducing a large self-heating effect.

Figure 3.3. Measured sensing PRT temperature rise as a function of $Q_{h}=I_{d c}{ }^{2} R_{h}$, shown for varied AC excitation frequency of 22.37, 12.95, and $2.97 \mathrm{~Hz}\left(i_{a c}=1.5 \mu \mathrm{A}\right)$ and obtained at $T_{0}$ $=375 \mathrm{~K}$. The inset shows the low $Q_{h}$ regime. Note that $22.97 \mathrm{~Hz}$ is the optimal frequency 
to achieve high temperature resolution, this is near the maximum frequency for the Delta mode $\left(f_{\max }=24 \mathrm{~Hz}\right.$, limited by instrumentation communication) and corresponds to the settings listed in Table 2.1.

Figure 3.4. Temperature dependence of contributions to the sensing noise equivalent temperature $\left(N E T_{s}\right)$ of the DC reversal technique ( $N E T_{\text {temperature drift }}$ and $\left.N E T_{\text {Johnson }}\right)$, shown in comparison to the total (pooled) standard deviation of the measured temperature rise, $\sigma_{\text {temp}}$, and the calculated delta mode instrumentation detection limit based on minimum resolution of $4.2-5 \mathrm{nV}$.

Figure 3.5. Measured temperature rise on the sensing $P R T, \Delta T_{s}$, as a function of heating power $Q_{h}$ detected using the $D C$ reversal technique with a $1.5 \mu \mathrm{A} A C$ excitation current at $22.37 \mathrm{~Hz} . \mathrm{T}_{0}=($ a) $375 \mathrm{~K}$, (b) $290 \mathrm{~K}$, (c) $75 \mathrm{~K}$, and (d) $30 \mathrm{~K}$. Error bars are defined as one standard deviation of $\Delta T_{s}\left(Q_{h}\right)$ over five separate measurement sets (one set is defined as $I_{d c}=0$ to $-I_{d c, \max }$ to $+I_{d c, \max }$ to 0 ). The measured total (pooled) standard deviation of the temperature rise, $\sigma_{\text {temp }}$, is shown for comparison at each $T_{0}$.

Figure 3.6. Measured sensing PRT temperature rise $\Delta T_{s}$ as a function of heating power $Q_{h}$ at 290 $K$. The DC reversal technique is measured with $1.5 \mu \mathrm{A} A C$ excitation current at 22.37 $\mathrm{Hz}$. The lock-in technique is measured with $1.5 \mu \mathrm{A}$ (peak-to-peak) AC excitation current at $199.03 \mathrm{~Hz}$ using a $1 \mathrm{M} \Omega$ precision resistor to convert the lock-in amplifier internal voltage source to a current source. The total (pooled) uncertainty of $\Delta T_{s}$, defined as $\sigma_{\text {temp }}$, measured by the lock-in method is $9.38 \mathrm{mK}$ while that of DC reversal technique is an order of magnitude lower at $1.59 \mathrm{mK}$.

Figure 3.7. (a) Total heat conducted through the six beams supporting the heating membrane to the environment, the the slope of $Q_{h}+Q_{L}$ as a function of $\Delta T_{h}+\Delta T_{s}$ yields $G_{b}$. (b) Corresponding temperature rise on the sensing membrane, $\Delta T_{s}$ as a function of $\Delta T_{h}-$ $\Delta T_{s}$, the slope yields the ratio of $G_{b} / G_{s}$.

Figure 3.8. (a) Measured beam conductance $G_{b}$ at different average temperature $T_{\text {avg. }}$ The uncertainty of $G_{b}$ is better than $2.2 \%$ within a $20 \mathrm{~K}$ temperature range. (b) Measured background conductance $G_{b g}$ at different average temperature $T_{a v g}$. The uncertainty of $G_{b g}$ is on the order of $2.47-6.75 \%$ within a $20 \mathrm{~K}$ temperature range. This is an impressive improvement from the traditional lock-in-based technique which exhibits uncertainty of $\sim 9.35-86 \%$ and requires a much higher temperature rise of $50 \mathrm{~K}$ at $\mathrm{T}_{0}$ $=77 \mathrm{~K}$. The lock-in data is reproduced from Ref. 44, which uses a voltage source and high-value resistor to generate $D C$ heating current. The red square indicates $G_{b g}$ measured with lock-in technique in this work by employing a DC current source and using two times higher AC sensing current than Ref. 44. The uncertainty of $G_{b g}$ is $9.2 \%$ within a $20 \mathrm{~K}$ temperature range and while it showed certain improvement from previous work but it is not as good as DC reversal technique. 


\section{List of tables}

Table 1.1. Summary of micro-resistance thermometry-based techniques. Noise equivalent temperature resolution of the sensing thermometer $\left(N E T_{s}\right)$ and noise equivalent thermal conductance resolution (NEG) are the critical performance parameters in these methods.

Table 2.1. Summary of the optimal settings of the Delta Mode (6221/2182A) for the suspended microthermometry technique using a $6517 B$ voltage source and ultra-precision resistor as a voltage-to-current converter. " $h$ " denotes heating PRT, " $s$ ” denotes sensing PRT.

Table 3.1. Summary of temperature and thermal conductance resolution for the DC reversal technique. The measured standard deviation of the sensing temperature rise, $\sigma_{\text {temp }}$, and the measured standard deviation of the background thermal conductance $\sigma_{G}$ compare favorably with the NETs and NEG values. 


\section{Chapter 1 - Introduction}

\subsection{Background}

Low dimensional materials such as carbon nanotubes ${ }^{1-6}$, inorganic nanowires ${ }^{7-12}$, organic nanofibers $^{13-15}$, superlattices ${ }^{16,17}$, and two dimensional materials ${ }^{18-24}$ have been the focus of significant research interest over the past two decades due to their unique thermal transport properties which can be significantly different than in their bulk form. In addition to establishing fundamental structure-property relationships in these materials, these investigations have also enabled novel thermal device applications ${ }^{25-29}$. Hence, further development of new experimental techniques for characterization of thermal transport in nanostructures remains an important area as advancement continues in the prediction, design, and synthesis of new materials.

\subsection{Suspended micro-thermometry measurement}

Several thermal measurement techniques have been developed for probing in-plane thermal transport properties in low dimensional materials, the most prominent of which are the suspended micro-thermometry ${ }^{2-4,} 11,19$, Raman thermometry ${ }^{5}$, 18, 30, bi-material atomic force microscopy (AFM) cantilever thermometry ${ }^{13}$, and steady-state Joule heating ${ }^{4,31-33}$ methods. Of these, the suspended micro-thermometry technique is the most common method to measure inplane thermal conductance in individual nanostructures as phonons are fully thermalized, in contrast to optothermal techniques ${ }^{34,35}$. Platinum resistance thermometers (PRTs) are used to measure the temperature and heat flow on the suspended microdevice as platinum's electrical 
Table 1.1. Summary of micro-resistance thermometry-based techniques. Noise equivalent temperature resolution of the sensing thermometer $\left(N E T_{s}\right)$ and noise equivalent thermal conductance resolution (NEG) are the critical performance parameters in these methods.

\begin{tabular}{|c|c|c|c|c|c|}
\hline $\begin{array}{c}\text { Temperature } \\
\text { Measurement } \\
\text { Scheme }^{\text {a) }}\end{array}$ & $\begin{array}{l}\text { Heating } \\
\left.\text { Current }{ }^{b}\right)\end{array}$ & $\begin{array}{l}\text { Sensing } \\
\left.\text { Current }{ }^{c}\right)\end{array}$ & $\mathrm{NET}_{s}$ & NEG & Comment \\
\hline Lock-in 3 & unmodulated & modulated & $\begin{array}{l}25 \mathrm{mK} \\
(300 \mathrm{~K})\end{array}$ & $\begin{array}{l}1 \mathrm{nW} / \mathrm{K} \\
(300 \mathrm{~K})\end{array}$ & $\begin{array}{l}\text { One of the first suspended micro-thermometry } \\
\text { techniques to measure the in-plane thermal } \\
\text { conductance of an individual nanostructure. } \\
\text { Background thermal conductance becomes an issue } \\
\text { when } G_{s} \text { is comparable to } G_{b g} \text { on the order of 200- } \\
400 \mathrm{pW} / \mathrm{K} \text {. }\end{array}$ \\
\hline $\begin{array}{c}\text { Lock-in, } \\
\text { Differentia|36 }\end{array}$ & unmodulated & modulated & $\begin{array}{l}10 \mathrm{mK} \\
(320 \mathrm{~K})\end{array}$ & $\begin{array}{c}100 \mathrm{pW} / \mathrm{K} \\
(320 \mathrm{~K})\end{array}$ & $\begin{array}{l}\text { Eliminates error contributed from background } \\
\text { thermal conductance, parasitic heat loss from the } \\
\text { supporting beams, and device asymmetry. However, } \\
\text { method involves laborious data analysis and } \\
\text { multiple measurement schemes. }\end{array}$ \\
\hline $\begin{array}{c}\text { Lock-in, } \\
\text { Differentia|37 }\end{array}$ & modulated & unmodulated & $\begin{array}{c}20 \mu \mathrm{K} \\
(280 \mathrm{~K})\end{array}$ & N/A & $\begin{array}{l}\text { Resistance-based high-resolution thermometer, } \\
\text { which improves signal-to-noise ratio through higher } \\
\text { common mode noise rejection. The differential } \\
\text { technique eliminates the error arising from ambient } \\
\text { temperature fluctuation, on the order of } 5 \mathrm{mK} \text {. }\end{array}$ \\
\hline $\begin{array}{c}\text { Lock-in, } \\
\text { Wheatstone } \\
\text { Bridge }^{38}\end{array}$ & modulated & unmodulated & $\begin{array}{l}50 \mu \mathrm{K} \\
(300 \mathrm{~K})\end{array}$ & $\begin{array}{c}0.25 \mathrm{pW} / \mathrm{K} \\
(300 \mathrm{~K})\end{array}$ & $\begin{array}{l}\text { Modification of the suspended micro-thermometry } \\
\text { technique which improves signal-to-noise ratio } \\
\text { using a Wheatstone bridge circuit to amplify the } A C \\
\text { signal while eliminating the error arising from the } \\
\text { ambient temperature fluctuation. }\end{array}$ \\
\hline $\begin{array}{l}\text { DC reversal } \\
\text { (this work) }\end{array}$ & unmodulated & modulated & $\begin{array}{l}1.6 \mathrm{mK} \\
(290 \mathrm{~K})\end{array}$ & $\begin{array}{l}13 \mathrm{pW} / \mathrm{K} \\
(290 \mathrm{~K})\end{array}$ & $\begin{array}{l}\text { Modification of the suspended micro-thermometry } \\
\text { technique which improves signal-to-noise ratio } \\
\text { through a measurement scheme benefitting from } \\
\text { improved common mode noise rejection over lock- } \\
\text { in amplifier-based techniques (200 dB versus } 100 \\
\text { dB). High throughput, simple measurement scheme, } \\
\text { fewer sources of error/noise. }\end{array}$ \\
\hline
\end{tabular}

a) Differential indicates adoption of a matching resistance to cancel the ambient temperature fluctuations. Wheatstone bridge indicates adoption of a Wheatstone bridge circuit to cancel the ambient temperature fluctuations.

b) Unmodulated indicates a steady-state temperature rise induced by a DC current, modulated indicates an oscillating temperature rise with a frequency $2 f$ induced by an AC current at $f$.

c) Unmodulated indicates detection of resistance by applying a DC current, modulated indicates detection using an AC current with a frequency $f$. 
resistance has a nearly-linear relationship with temperature and large temperature coefficient of resistance (TCR) over a wide range of temperatures. Based upon the original reports ${ }^{2}{ }^{3}$, several different electrical resistance measurement techniques have been developed to achieve higher temperature and thermal conductance resolution in the suspended micro-thermometry method ${ }^{36,38 \text {, }}$ 39. A summary of these techniques is shown in Table 1.1 and Figure 1.1.

In a pioneering work published a decade ago, Philip Kim et al. ${ }^{2}$ developed a suspended micro-thermometry device and used it to probe the in-plane thermal conductance of a multiwalled carbon nanotube, where the suspended microdevice containing two built-in platinum resistors was used to measure the temperature and heat flow across the sample. In this and other previous lock-in-based measurement schemes, the thermal conductance resolution was reported on the order of $1 \mathrm{nW} / \mathrm{K}$. The presence of temperature fluctuations in the sample chamber and background thermal conductance through the device, residual gases, and radiation are dominant sources of errors when the sample thermal conductance is comparable to or smaller than the background thermal conductance, on the order of $300 \mathrm{pW} / \mathrm{K}$ at room temperature.

Sadat $e l a l .{ }^{37,} 39$ have analyzed the temperature resolution of this technique in four different scenarios and demonstrated a temperature resolution of $\sim 20 \mu \mathrm{K}$ at $280 \mathrm{~K}$ by measuring modulated temperature changes on the PRT's resistance with an unmodulated sensing current and a matching PRT which has nearly the same resistance and temperature drift as the sensing PRT. In particular, detecting an unmodulated temperature change requires instrumentation with large dynamic range to eliminate the ambient temperature drift at the same time. First, a large sensing current and PRT with a large electrical resistance was used to improve signal-to-noise ratio but it should be noted that these approaches are limited by the microdevice fabrication and self-heating issues. 

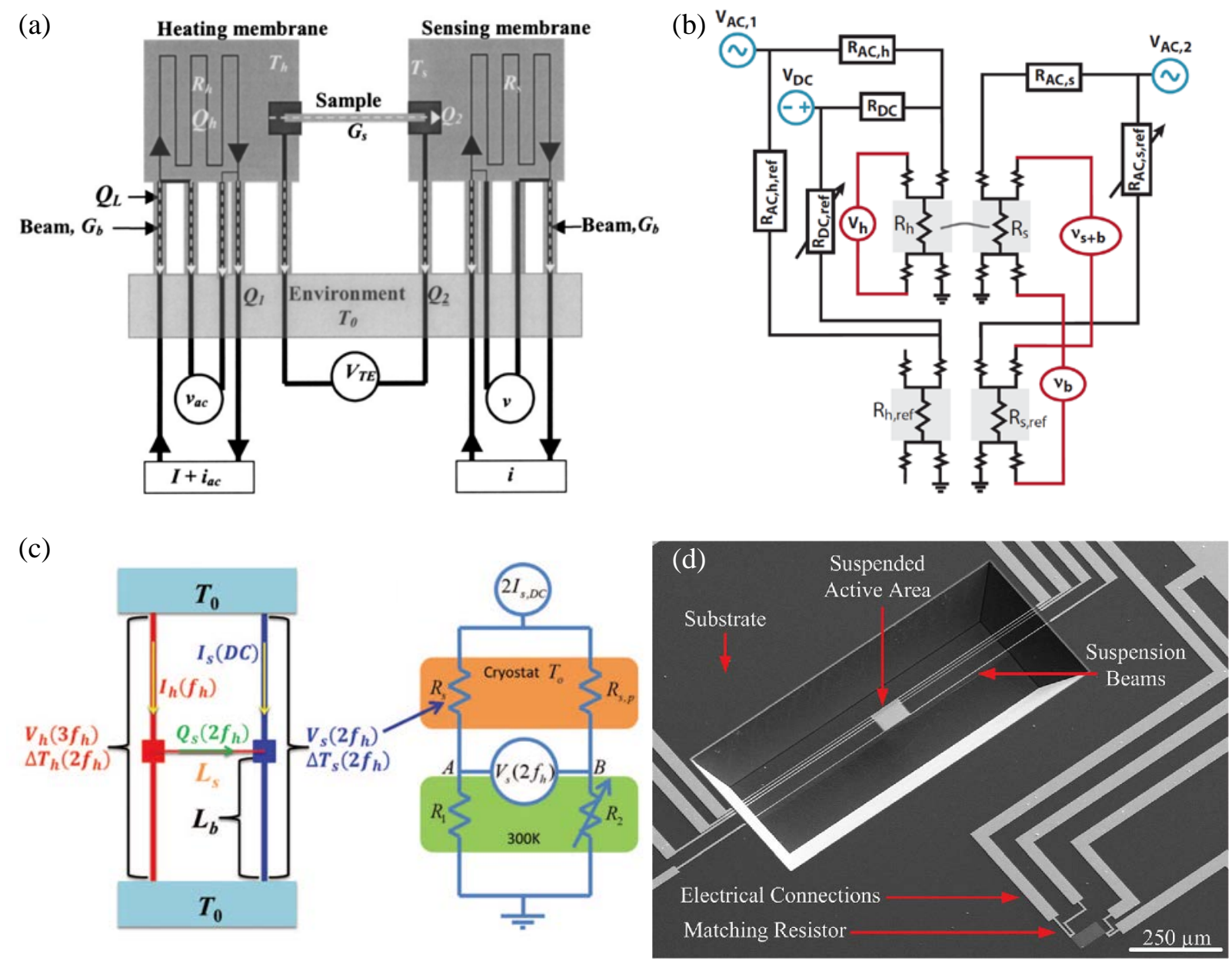

Figure 1.1. Suspended micro-thermometry measurement schemes. (a) Electrical and thermal circuits of the suspended micro-thermometry device with unmodulated heating current and modulated sensing current (reproduced from Ref. 3). (b) Electrical circuit of the suspended microthermometry device adapted by a differential measurement scheme. The matching device allows this technique to isolate the background thermal conductance during the measurement (reproduced from Ref. 36), (c) A modified suspended micro-thermometry device adapted by a Wheatstone bridge scheme with modulated heating current and unmodulated sensing current (reproduced from Ref. 38). The Wheatstone bridge circuit is used to eliminate the temperature drift from the sample chamber. (d) A single-pad suspended micro-thermometry device with two PRTs on the suspended membrane adapted by a differential scheme with modulated heating current and unmodulated sensing current (reproduced from Ref. 37). The matching resistor is used to eliminate the temperature drift from the sample chamber.

Previous improvements on the micro-thermometry technique have resulted in two major contributions. First, the voltage noise and ambient temperature drift that arises from an unmodulated temperature signal can be eliminated using a high frequency detecting current with 
a lock-in amplifier and a differential scheme ${ }^{36,39}$, but a complicated setup and data analysis is involved to achieve this high temperature and thermal conductance resolution. Second, a temperature signal modulated at specific frequency with an unmodulated sensing current can further improve temperature resolution ${ }^{37,38}$, however, the attenuation of modulated temperature due to the large thermal time constant of the suspended microdevice becomes an issue during the thermal conductance measurement.

\subsection{Motivation and scope of the study}

In this work, I have developed a high throughput suspended micro-thermometry measurement scheme involving less instrumentation and simple data analysis. Specifically, we have introduced a bipolar DC reversal measurement which is a well-established alternative technique to remove offset and low frequency noises during measurement. This modern DC reversal technique exhibits less than one half the amount of white noise and an order of magnitude lower $1 / f$ noise than the most commonly used lock-in amplifiers ${ }^{40}$. As a result, I have demonstrated resolution near the instrumentation limit of this technique: a sensing noise equivalent temperature $\left(\mathrm{NET}_{\mathrm{s}}\right.$ ) of 2.62 and $1.12 \mathrm{mK}$ and a noise equivalent thermal conductance (NEG) of 26.42 and 1.73 $\mathrm{pW} / \mathrm{K}$ at an ambient temperature of 375 and $30 \mathrm{~K}$ respectively. The NET reaches a minimum of $0.96 \mathrm{mK}$ at $75 \mathrm{~K}$ without the need for using complicated schemes involving matching resistors or Wheatstone bridge to cancel the ambient temperature drift. 


\section{Chapter 2 - Thermal conductance measurement}

\subsection{Measurement setup}

The microfabricated suspended device consists of two symmetric adjacent low stress silicon nitride $\left(\mathrm{SiN}_{x}, 22 \mu \mathrm{m}\right.$ by $22 \mu \mathrm{m}$ ) membranes each suspended by six $400 \mu \mathrm{m}$ long by $2 \mu \mathrm{m}$ wide $\mathrm{SiN}_{x}$ beams. One $35 \mathrm{~nm}$ thick, 250 nm wide and $350 \mu \mathrm{m}$ long serpentine platinum resistance heater/thermometer is patterned on each membrane. One $1 \mu \mathrm{m}$ wide by $16.25 \mu \mathrm{m}$ long inner electrode and one $1.25 \mu \mathrm{m}$ wide by $19 \mu \mathrm{m}$ long outer electrode are also patterned on each membrane. The heater/thermometer and electrodes are connected to electrical contact pads with $400 \mu \mathrm{m}$ long by $2 \mu \mathrm{m}$ wide Pt metal lines, as shown in Figure. 2.1. The silicon substrate beneath the suspended membranes is completely removed. The detail of the fabrication processes can be found in Ref. 41.

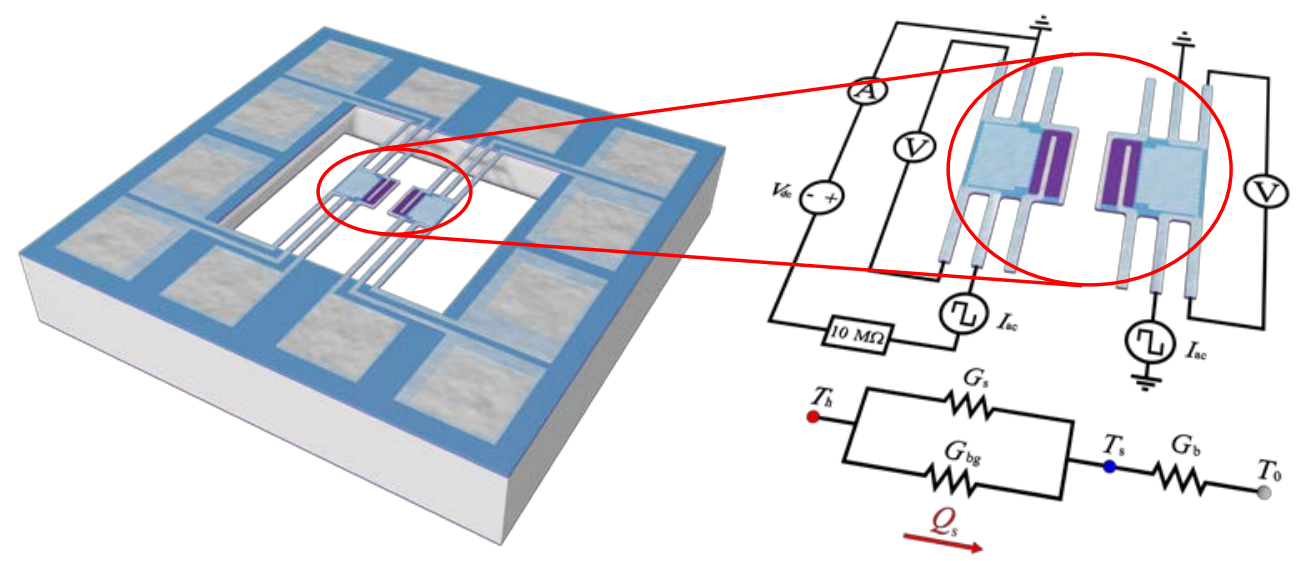

Figure 2.1. Schematic of the suspended microdevice and circuit diagram of the DC reversal technique to measure the electrical resistances of the heating and sensing PRTs on a suspended microdevice. Shown below is the corresponding thermal circuit. A $10 \mathrm{M} \Omega$ ultra high precision resistor is used to convert the voltage source into a DC current source. A high input impedance $\left(10^{14} \Omega\right)$ programmable current source and high input impedance nanovoltmeter $\left(>10^{12} \Omega\right)$ are connected to obtain the 4-probe differential voltage on each PRT. 


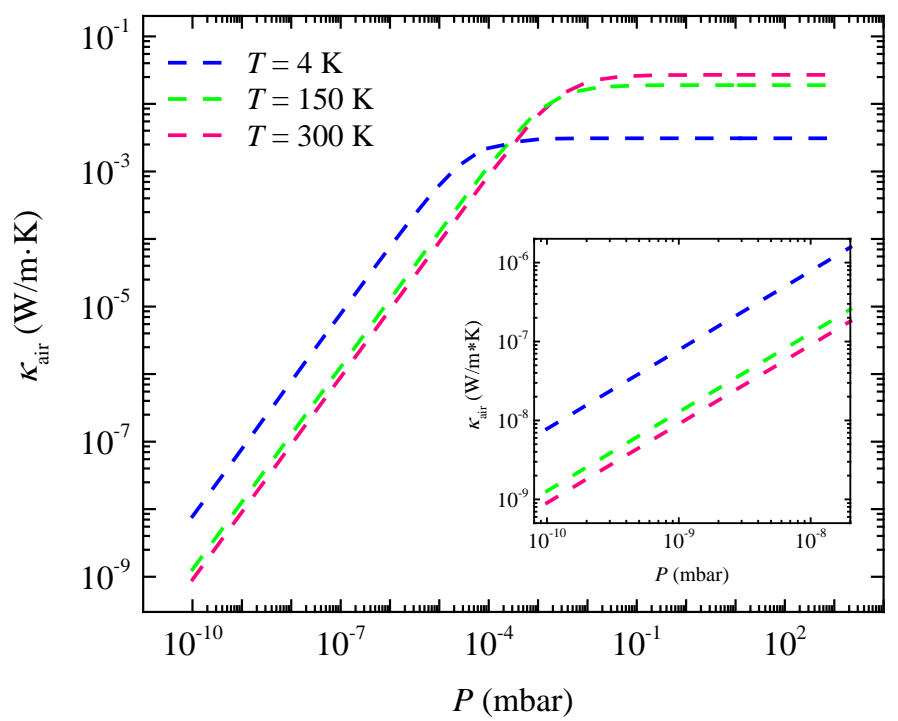

Figure 2.2. Kinetic theory calculation of the thermal conductivity of residual air molecules, $\kappa$ air, inside an enclosure chamber with a diameter of 2.5 inches ( sample chamber diameter) as a function of pressure, $P$, from $10^{-10}$ to 1000 mbar at certain ambient chamber temperature $(T=4$, 150 , and $300 \mathrm{~K}$ ) by kinetic theory of gases. inset shows corresponded air thermal conductivity within cryostat chamber pressure range $\left(10^{-10}\right.$ to $10^{-8}$ mbar $)$.

The suspended microdevice was placed in a Janis SHI-4ST-UHV closed cycle cryostat connected to an Oerlikon Leybold TURBOVAC TW250S/TRIVAC D16BCS turbo pumping system providing a vacuum environment better than $10^{-8}$ mbar during thermal transport measurements (Figure 2.3). The cryostat sample temperature was controlled by a Lakeshore 336 cryogenic temperature controller which provided a measured ambient temperature stability of better than $2 \mathrm{mK}$ (Figure 2.3). The suspended microdevice contains two symmetric adjacent silicon nitride $\left(\mathrm{SiN}_{x}\right)$ membranes each suspended by six long $\mathrm{SiN}_{x}$ beams. A serpentine PRT is fabricated on each membrane and it connects to four contact pads by platinum lines on the suspended beams. The heating PRT was electrically heated by an unmodulated current provided by a Keithely 6517B electrometer in series with a $10 \mathrm{M} \Omega$ high precision resistor (Caddock USF370-10.0M-0.01\%5ppm). The DC current passing through the device was directly measured by the low-impedance 


\section{(a)}

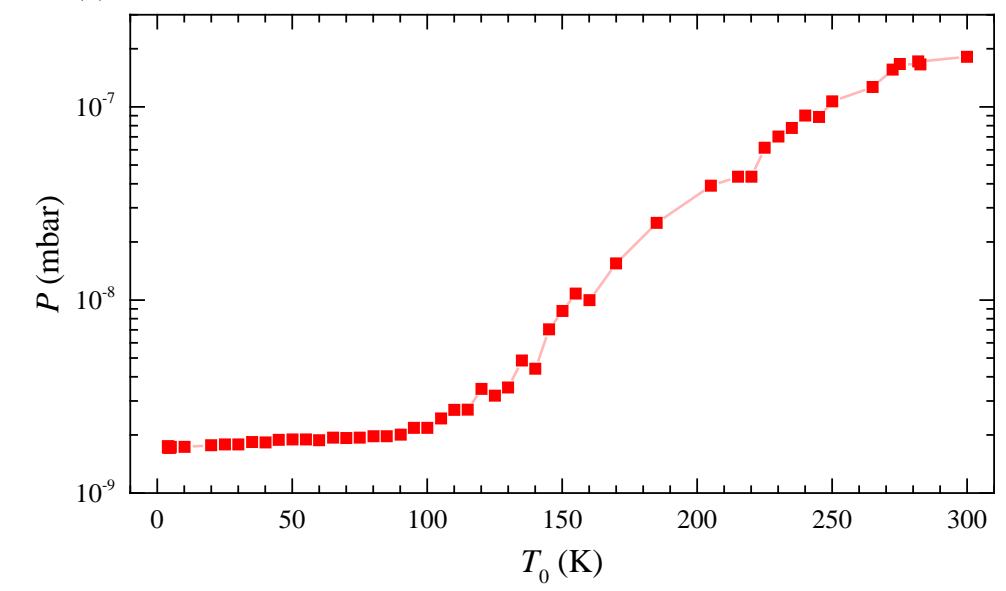

(b)

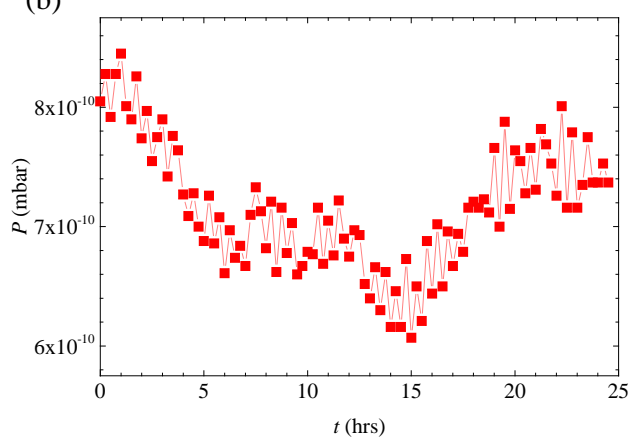

(d)

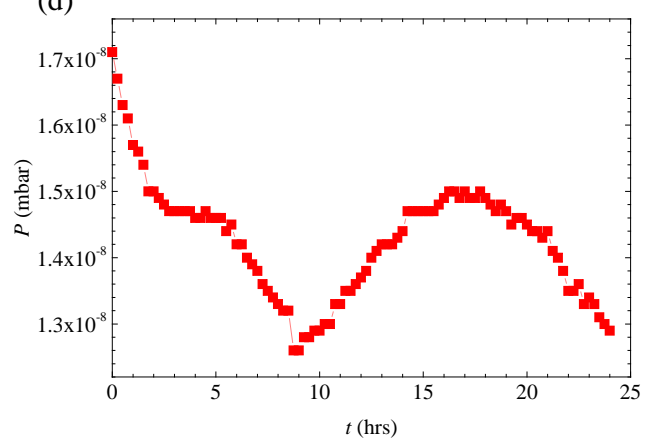

(c)
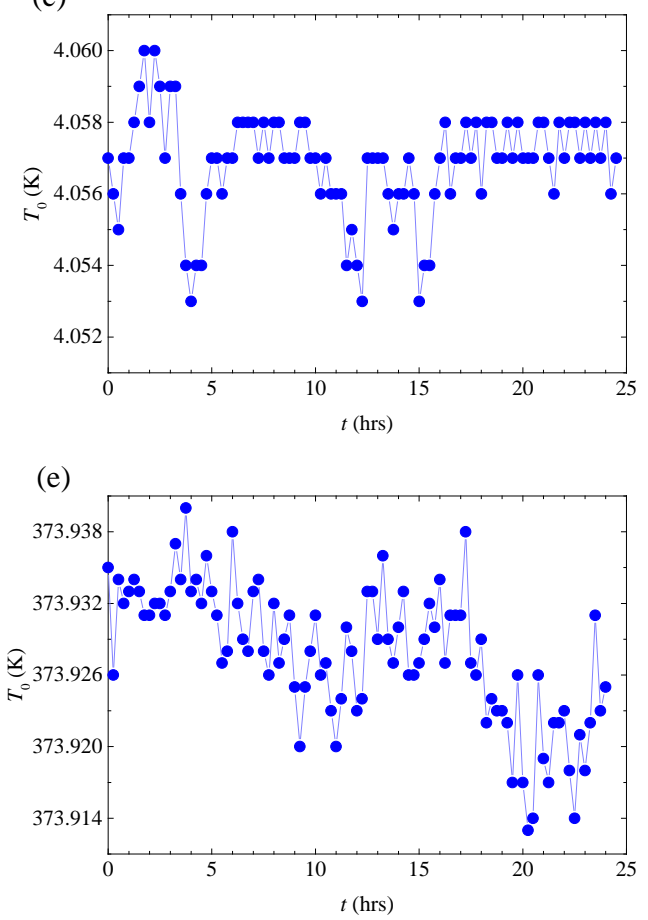

Figure 2.3. (a) Ultra high vacuum cryostat chamber pressure as a function of temperature recorded at the sample mount, $T_{0}$ over a temperature range from 4 to $300 \mathrm{~K}$. (b) Measured cryostat chamber pressure as a function of time at $4 \mathrm{~K}$ sample mount temperature, the system maintained vacuum better than $8.5 \times 10^{-10}$ mbar over 24 hours. (c) Measured cryostat sample mount temperature as a function of time at $4 \mathrm{~K}$, it maintained a stability better than $1 \mathrm{mK}$ over 24 hours. (d) Measured cryostat chamber pressure as a function of time at $375 \mathrm{~K}$ sample mount temperature, it maintained vacuum better than $1.5 \times 10^{-8}$ mbar over 24 hours. (e) Measured cryostat sample mount temperature as a function of time at $375 \mathrm{~K}$, it maintained a stability better than $20 \mathrm{mK}$ over 24 hours. Data depicted in (b) and (c) were collected while the temperature of the heater was set at $4.0000 \mathrm{~K},(e)$ and $(f)$ were collected while the temperature of heater was set at $375.000 \mathrm{~K}$. The temperature drift in the thermal conductance measurement was much smaller than above data because each measurement set was taken within 0.5 hours. 
input of the Keithley 6517B. During the measurement, a certain amount of this heat is transferred to the adjacent sensing membrane and PRT through parallel mechanisms: (i) through the nanostructure, (ii) through the thermal sink (the silicon substrate), and (iii) through radiation and residual gas conduction. Mechanisms (ii) and (iii) are denoted background thermal conductance, $G_{\mathrm{bg}}$. The uncertainty arising from the thermal radiation contributes less than $2 \%$ to the thermal conductance of the beam and sample over 30 to $400 \mathrm{~K}^{42}$. At $10^{-8} \mathrm{mbar}$ and $300 \mathrm{~K}$, thermal conductivity of air is on the order of $10^{-7} \mathrm{~W} /(\mathrm{m} \cdot \mathrm{K})$, as shown in Figure 2.2 and yields thermal conductance of less than $5 \mathrm{pW} / \mathrm{K}$ which accounts for $1.5 \%$ of the total $G_{\mathrm{bg}}$.

\subsection{Data processing}

A schematic of the measurement is shown in Figure 2.1. Both of the PRTs serve as thermometers to measure the temperature rise on each suspended membrane, which is determined by the PRT's temperature-dependent electrical resistance and its temperature coefficient of resistance (TCR) using two Keithley 6221/2182A Delta-mode systems. The electrical resistances of the heating membrane PRT and each Pt lead are denoted as $R_{\mathrm{h}}$ and $R_{\mathrm{L}}$ respectively. A Joule heat, $Q_{\mathrm{h}}=I_{\mathrm{dc}}{ }^{2} R_{\mathrm{h}}$, is generated when a DC current $I_{\mathrm{dc}}$ passes through the heating membrane and causes its temperature to rise from $T_{0}$ to $T_{\mathrm{h}}$. Meanwhile, the two current-carrying Pt leads generate and dissipate Joule heat, $2 Q_{\mathrm{L}}=2 I_{\mathrm{dc}}{ }^{2} R_{\mathrm{L}}$, due to the DC current. The uniform temperature on the heating membrane is a justified assumption since the internal thermal resistance of the PRT is two orders of magnitude smaller than the thermal resistance of the six long Pt leads connecting it to the silicon chip at ambient temperature $T_{0}{ }^{42}$. A certain portion of the Joule heat, $Q_{\mathrm{s}}$, is transferred from the heating membrane through the nanostructure to to the sensing membrane. The sensing membrane is raised from $T_{0}$ to $T_{\mathrm{s}}$, which is assumed uniform on the sensing membrane by the 
previous justification. This amount of heat then is conducted to the silicon heat sink at $T_{0}$ through the six beams supporting the sensing membrane. With the conservation of energy, the remaining heat, $Q_{1}=Q_{\mathrm{h}}+2 Q_{\mathrm{L}}-Q_{\mathrm{s}}$, is conducted to the silicon chip through the six beams supporting the heating membrane. The thermal conductance of six beams supporting each membrane $G_{\mathrm{b}}$ and the total sample thermal conductance $G_{\mathrm{s}}$ from the heating membrane to sensing membrane are determined with the thermal circuit in Figure 2.1 as

$$
\begin{aligned}
& G_{\mathrm{b}}=\frac{1}{R_{\mathrm{b}}}=\frac{Q_{\mathrm{h}}+Q_{\mathrm{L}}}{\Delta T_{\mathrm{h}}+\Delta T_{\mathrm{s}}} \text { and } \\
& G_{\mathrm{s}}=\frac{Q_{\mathrm{s}}}{\Delta T_{\mathrm{h}}-\Delta T_{\mathrm{s}}}=G_{\mathrm{b}} \frac{\Delta T_{\mathrm{s}}}{\Delta T_{\mathrm{h}}-\Delta T_{\mathrm{s}}} \text {, respectively. }
\end{aligned}
$$

The temperature of the heating membrane and sensing membrane, $T_{\mathrm{h}}$ and $T_{\mathrm{s}}$ respectively, are accurately determined by a DC reversal 4-point differential electrical resistance measurement, as depicted in Figure 2.1. A small positive DC current $(1.5 \mu \mathrm{A})$ is passed through the PRT and the voltage $V_{1}$ across the PRT is measured, then the DC current is reversed $(-1.5 \mu \mathrm{A})$ and a second voltage $V_{2}$ is recorded. The positive DC current $(1.5 \mu \mathrm{A})$ is applied again and a third voltage $V_{3}$ is measured. A three point moving average algorithm is used to determine the final voltage responses, where $V_{\text {final }}=\left(V_{1}-2 V_{2}+V_{3}\right) / 4$. This data processing is completed internally and the DC reversal system outputs the final voltage and resistance responses corresponding to the DC current $(1.5 \mu \mathrm{A})$ I apply.

The change of the temperature caused by DC heating results in an electrical resistance change of the PRT which is interpreted back to a temperature rise using the measured TCR of each PRT, $\alpha_{i} \equiv\left[\partial R_{i}(T) / \partial T\right] / R_{i}(T), i=\mathrm{h}$, s. To obtain steady-state resistance versus temperature and TCR, I have measured the PRT resistances every $\sim 0.4 \mathrm{~K}$ while the temperature of the chamber was slowly cooled at a rate of $3.33 \mathrm{mK} / \mathrm{s}$ from 375 to $4 \mathrm{~K}$, as shown in Figure 2.4. The 
(a)

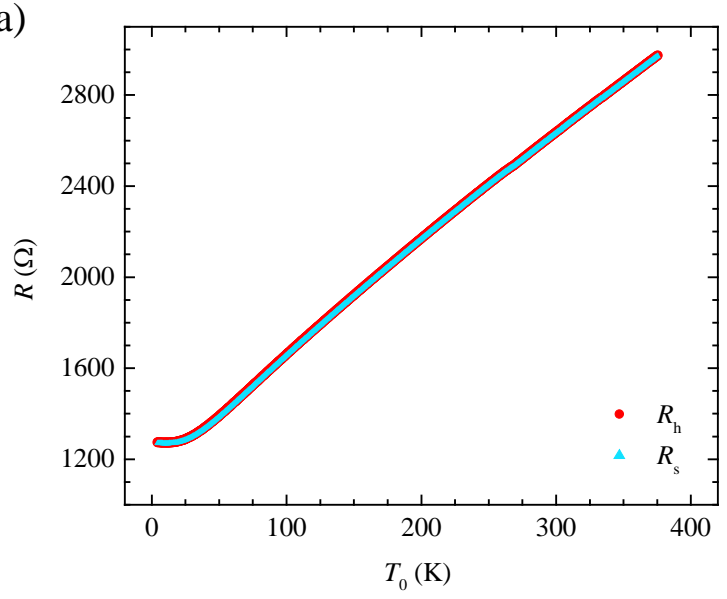

(b)

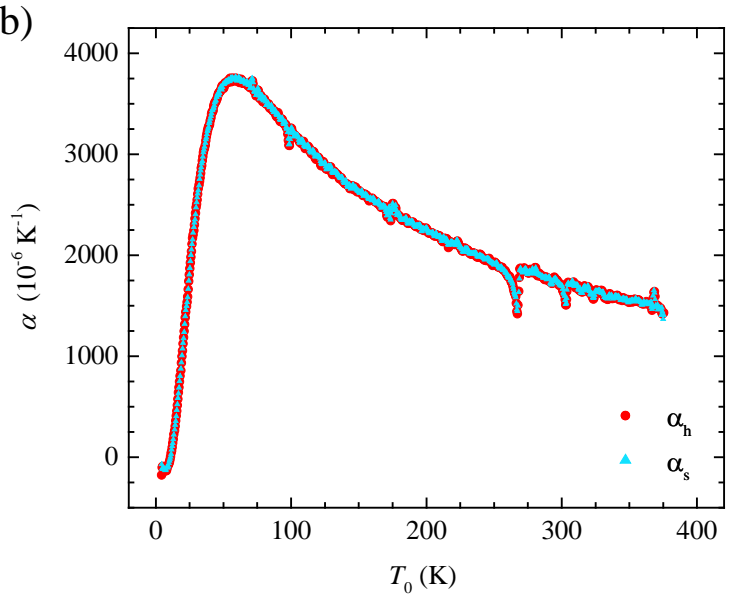

Figure 2.4. Electrical resistance, $R$, and temperature coefficient of resistance (TCR), $\alpha$, of the heating and sensing PRTs as a function of temperature recorded at the sample mount, $T_{0}$. (a) Measured heating and sensing PRT electrical resistances, $R_{h}$ and $R_{s}$ respectively, over a temperature range from 4 to $375 \mathrm{~K}$ and (b) the corresponding TCR of heating and sensing PRTs, $\alpha_{\mathrm{h}}$ and $\alpha_{\mathrm{s}}$ respectively. The TCR at each temperature point is calculated over 15 measured resistance points which corresponds to a local temperature range of approxiately $T_{0} \pm 3 \mathrm{~K}$.

corresponding TCR of each PRT at each ambient temperature point $T_{0}$ is used to calculate the temperature change caused by the DC joule heating. The TCRs at each $T_{0}$ are determined over a $T_{0} \pm 3 \mathrm{~K}$ temperature range to define a local $\alpha$ for use in Eqs. 3-4. Consequently, the resulting temperature rise on the sensing membrane $\Delta T_{\mathrm{s}}$ is a function of the $I_{\mathrm{dc}}$ applied on the heating PRT and can be determined as

$$
\Delta T_{\mathrm{s}}\left(I_{\mathrm{dc}}\right)=\frac{1}{\alpha_{\mathrm{s}}}\left(\frac{R_{\mathrm{s}}\left(I_{\mathrm{dc}}\right)-R_{\mathrm{s}}\left(I_{\mathrm{dc}}=0\right)}{R_{\mathrm{s}}\left(I_{\mathrm{dc}}=0\right)}\right) .
$$

Measurement of the temperature rise on the heating membrane is complicated by the copling between AC and DC currents. An AC current $i_{\mathrm{ac}}$ with a frequency $f_{\mathrm{h}}$ is coupled to the much larger DC heating current during the electrical resistance measurement and this AC current will generate modulated heating at frequency $2 f_{\mathrm{h}}$ at when $f_{\mathrm{h}}$ is low. Shi et al. ${ }^{3}$ have experimentally demonstrated a factor of 3 difference between the low frequency and high frequency limits of an 
unmodulated temperature rise calculation when the DC current heating is coupled with a sinusoidal AC current. The AC and DC coupling effect remains important in this work because I am employing a square wave AC current in our measurement scheme. Joule heating, $Q_{\mathrm{ac}+\mathrm{dc}}=\left[I_{\mathrm{dc}}+\right.$ $\left.i_{\mathrm{ac}}\left(f_{\mathrm{h}}\right)\right]^{2} R_{\mathrm{h}}$, is generated on the heating membrane by the $\mathrm{AC}+\mathrm{DC}$ current. This modulated heating will yield a nontrivial component in $T_{\mathrm{h}}$ when the frequency of the AC current is much smaller than $1 /(2 \pi \tau)$, where $\tau$ is the thermal time constant of the suspended microdevice. Thus the measured resistance rise of the heating PRT, $\Delta R_{\mathrm{h}}$, is affected by this AC + DC heating effect in the low frequency regime. Thus the temperature rise $\Delta T_{\mathrm{h}}$ is a function of $I_{\mathrm{dc}}$ applied on the heating PRT can be determined as

$$
\Delta T_{\mathrm{h}}\left(I_{\mathrm{dc}}\right)=\frac{1}{\zeta \alpha_{\mathrm{h}}}\left(\frac{R_{\mathrm{h}}\left(I_{\mathrm{dc}}\right)-R_{\mathrm{h}}\left(I_{\mathrm{dc}}=0\right)}{R_{\mathrm{h}}\left(I_{\mathrm{dc}}=0\right)}\right), \begin{cases}\zeta=3, & f_{\mathrm{h}}<<1 /(2 \pi \tau) \\ \zeta=1, & f_{\mathrm{h}}>1 /(2 \pi \tau)\end{cases}
$$

To investigate the waveform-dependence of the frequency-dependent resistance rise, I have measured the $\Delta R_{\mathrm{h}}\left(f_{\mathrm{h}}\right)$ by a lock-in technique using a $1 \mu \mathrm{A}$ peak-to-peak excitation current in the frequency range from 0.8 to $5864 \mathrm{~Hz}$ for square, sine, and triangle waveforms while DC heating is applied (Figure 2.5). The factor $\zeta$ does not show a significant change with different types of AC waveform, where the normalized resistance change due to DC heating $\Delta R_{\mathrm{h}}\left(f_{\mathrm{h}}\right) / \Delta R_{\mathrm{h}}\left(f_{\mathrm{h}}=1 \mathrm{~Hz}\right)$ corresponds to $\zeta / 3$. Furthermore, the cut-off frequency between the low and high frequency regimes increases with temperature since $\tau$ decreases with decreasing temperature. As shown in Figure 2.6, I observed a higher cutoff frequency at $4 \mathrm{~K}$ than $375 \mathrm{~K}$ as $\tau$ is smaller at $4 \mathrm{~K}$ than at $375 \mathrm{~K}$. 


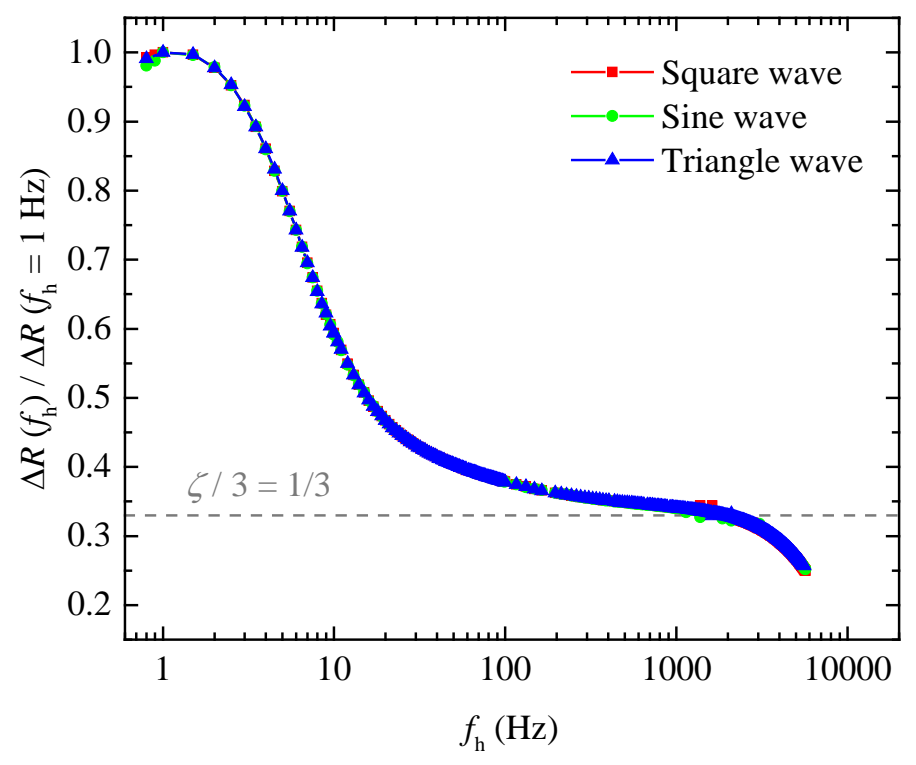

Figure 2.5. Normalized first harmonic component of the measured resistance rise of the heating $P R T$ as a function of the frequency of AC current coupled to the DC heating current for different $A C$ waveforms at $290 \mathrm{~K}$. The value of $\zeta$ in Eq.4 can be determined by the following relationship, $\zeta=3 \Delta R_{h}\left(f_{h}\right) / \Delta R_{h}\left(f_{h}=1 \mathrm{~Hz}\right)$. Note, the DC heating current here was provided by a Keithley 6221 .

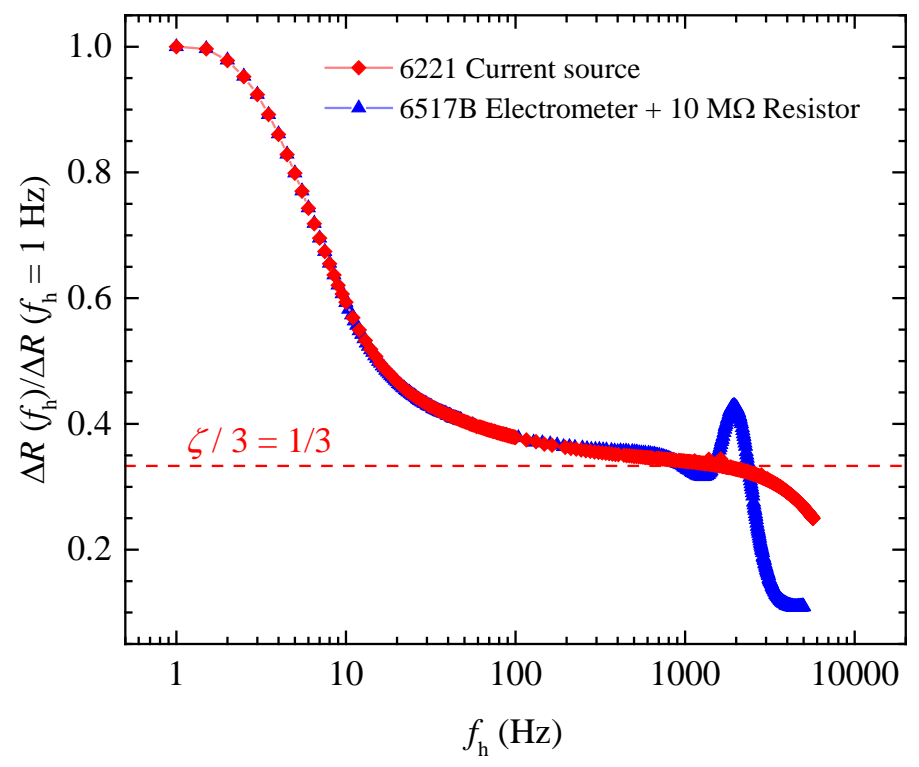

Figure 2.6. Normalized first harmonic component of the measured resistance rise of the heating PRT as a function of the frequency of AC current coupled to the DC heating with a lock-in technique, measured using a Keithley 6221 DC current source and a Keithley 6517B electrometer with a $10 \mathrm{M} \Omega$ precision resistor at $290 \mathrm{~K}$. The value of $\zeta$ in Eq. 4 can be determined by the following relationship, $\zeta=3 \Delta R_{h}\left(f_{h}\right) / \Delta R_{h}\left(f_{h}=1 \mathrm{~Hz}\right)$. 
The DC current provided by a Keithley 6517B electrometer and large resistor introduced unknown noises on the measured resistance rise as function of heating frequency. I have compared the resistance rise measured with a lock-in technique using a Keithley 6221 DC current source and Keithley 6517B in Figure 2.6. The lock-in technique picked up unpredicted noise when using the Keithley 6517B electrometer, consequently, DC current sourced with a Keithley 6517B and largevalue resistor is not recommended to use when the lock-in technique is employed to measure the measured resistance rise. In this thesis, a Keithley 6221 has been used as the DC current source when resistance has been measured with lock-in amplifiers.

I have also compared the resistance rise measured with a DC reversal technique to the resistance rise measured with a lock-in technique in Figure 2.7. The frequency of the DC reversal technique is based on the current source delay time, nanovoltmeter measuring time (number of power line cycles), and instrument communication time. We calculate the frequency based on the average measured timestamp, reported twice per period by the instrumentation. The frequencydependent resistance rise of the DC reversal technique was then used as a reference to determine the cut-off frequency defined as $\Delta R_{\mathrm{h}}\left(f_{\mathrm{h}}\right) / \Delta R_{\mathrm{h}}\left(f_{\mathrm{h}}=1 \mathrm{~Hz}\right)=0.998$, which is $12.94,6.39,3.02$, and 2.97 $\mathrm{Hz}$ at 4, 75, 290, and $375 \mathrm{~K}$ respectively. As our technique is designed for use in the low frequency regime, $3 \mathrm{~Hz}$ is appropriate over the full temperature range of $4-375 \mathrm{~K}$, ensuring $\zeta=3$ in Eq. 4. 


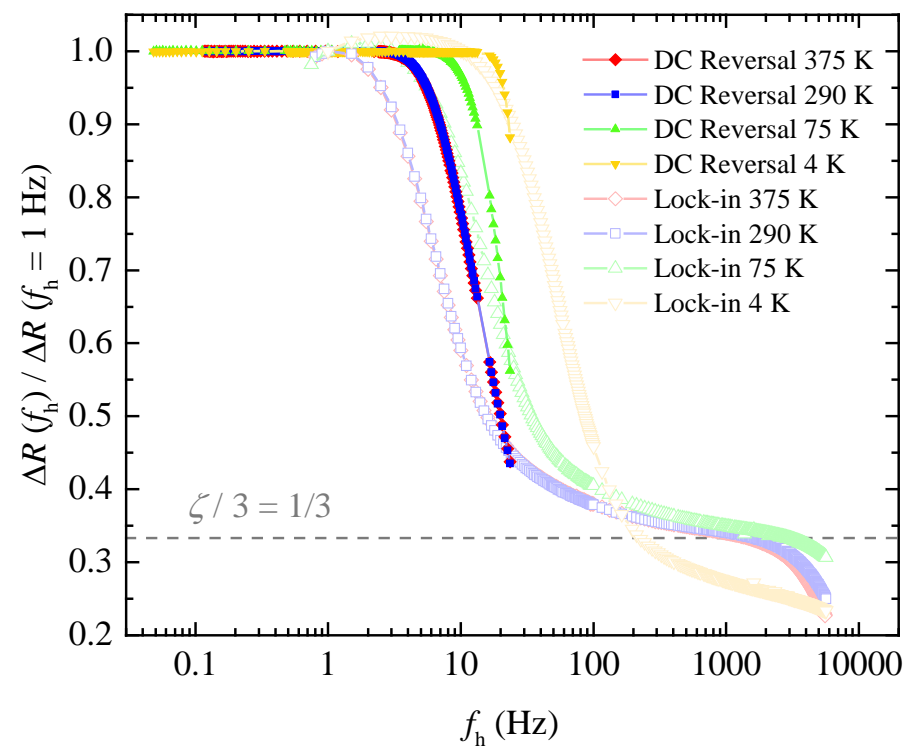

Figure 2.7. Normalized first harmonic component of the measured resistance rise of the heating PRT as a function of the frequency of AC current coupled to the DC heating current at 375, 290, and $75 \mathrm{~K}$ obtained by the DC reversal technique and by the lock-in technique with square wave excitation. The value of $\zeta$ in Eq.4 can be determined by following relationship, $\zeta=$ $3 \Delta R_{h}\left(f_{h}\right) / \Delta R_{h}\left(f_{h}=1 \mathrm{~Hz}\right)$. Note, the DC heating current was provided by a Keithley 6221 when the lock-in technique was used. 


\subsection{DC reversal technique}

I have introduced a bipolar DC reversal technique to measure the 4-probes electrical resistances of each PRT which is a well-established alternative technique to remove offset and low frequency noises during measurement. This modern technique exhibits less than one half the amount of white noise and an order of magnitude lower $1 / f$ noise than the most commonly used lock-in amplifiers ${ }^{40}$. Generally, the DC reversal system (Keithley $6221+2182 \mathrm{~A}$ ) performs a resistance measurement with following steps: (i) the 2182A nanovoltmeter triggers the 6221 current source to provide a positive current to the PRT, (ii) the 6221 sends a trigger signal to the 2182A after an operator-defined current delay time, (iii) the 2182A measures the voltage $V_{1}$ with an operator-defined measuring time (number of power line cycles), (iv) the 2182A sends the a trigger signal to stop the current source, (v) steps (i) to (iv) are repeated with a negative current and the voltage $V_{2}$ is recorded, (vi) steps (i) to (iv) are repeated again with a positive current and voltage $V_{3}$ is recorded, (vii) a three point moving average algorithm is used to determine the final voltage responses, where $V_{\text {final }}=\left(V_{1}-2 V_{2}+V_{3}\right) / 4$. The voltage $V_{\text {final }}$ is then associated with the operator-set current, $i_{\mathrm{ac}}$, to calculate the resistance of the PRT (Figure 2.8). The optimal conditions

for this technique are shown in Table 2.1 and have been used to measure the background thermal conductance in Chapter 3. 


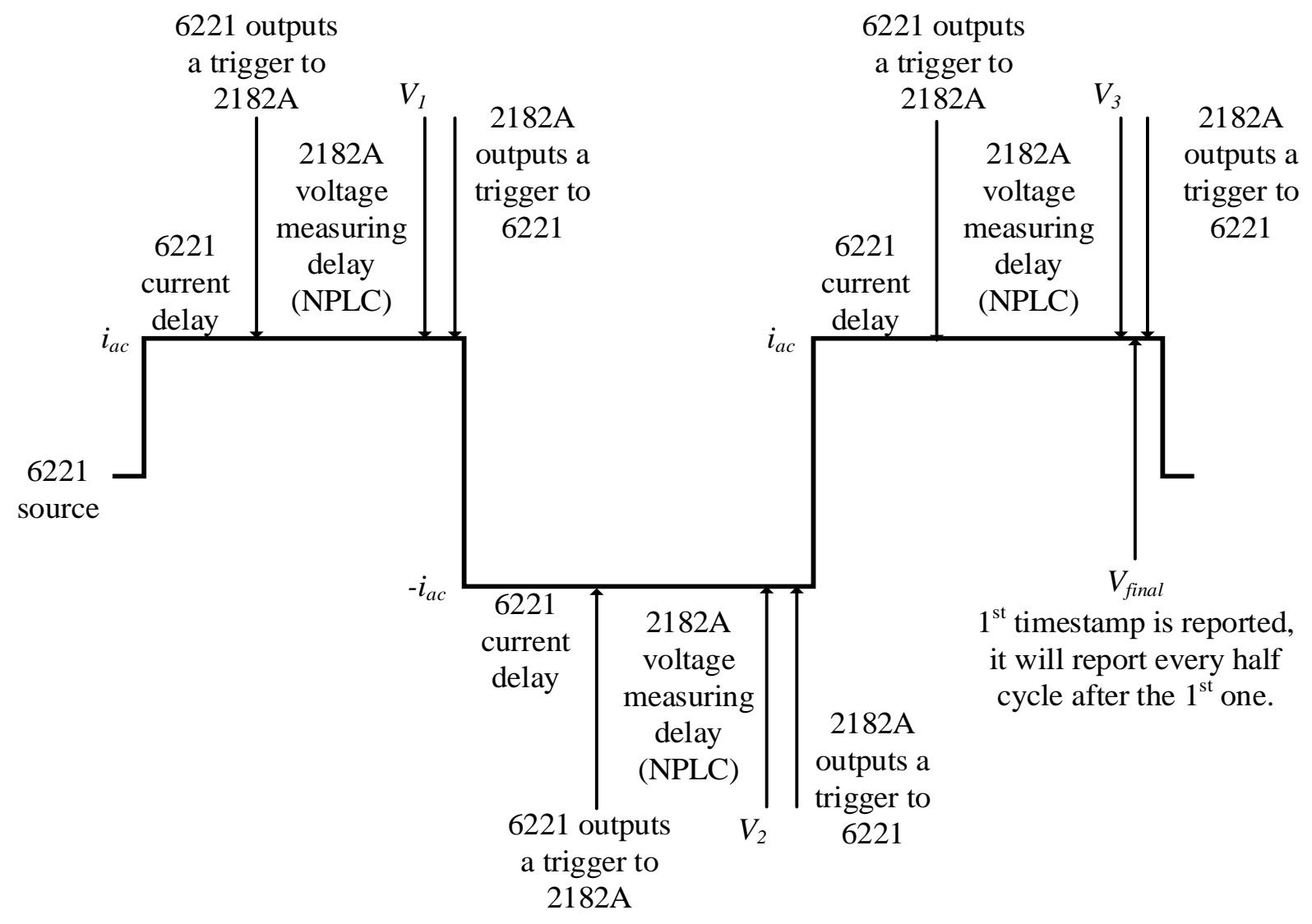

Figure 2.8. Schematic of the Keithley 6221 current source and Keithley 2182A nanovoltmeter DC reversal measurement technique (Delta Mode) data processing. The time period is not shown to scale. 
Table 2.1. Summary of the optimal settings of the Delta Mode (6221/2182A) for the suspended microthermometry technique using a $6517 \mathrm{~B}$ voltage source and ultra-precision resistor as a voltage-to-current converter. " $h$ " denotes heating PRT, "s" denotes sensing PRT.

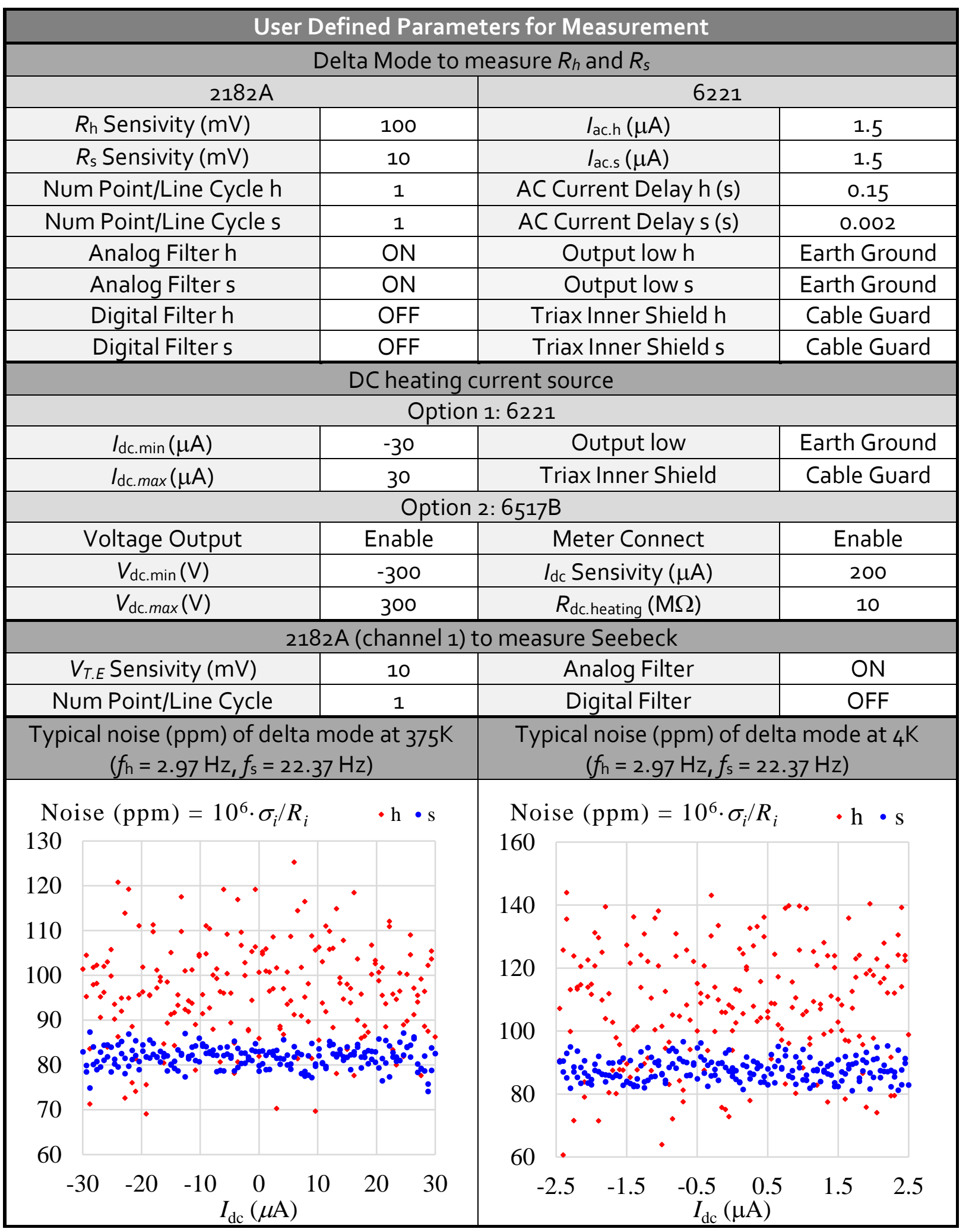




\section{Chapter 3 - Temperature and background thermal conductance resolution}

\subsection{Noise analysis}

Resistance-based thermometry is based on temperature-dependent electrical resistance, so that the measured resistance can be correlated with the temperature of the object to which the PRT is attached. On the sensing membrane, where only an AC signal is used in the resistance measurement, Eq. 3 can be used to convert the measured resistance change to temperature change. Thus, the noise equivalent temperature of the sensing PRT $\left(\mathrm{NET}_{\mathrm{s}}\right)$ is calculated based on Eq. 3 and the lowest total voltage noise in the electrical resistance measurement $\Delta V_{\text {noise }}$ as

$$
\mathrm{NET}_{\mathrm{s}}=\Delta T_{\text {Resolution }}=\frac{\Delta V_{\text {noise }}}{\alpha i_{\mathrm{ac}} R_{\mathrm{s}}(T)}
$$

Improving $\mathrm{NET}_{\mathrm{s}}$ can be achieved by employing a larger resistance PRT and larger sensing current. However, self-heating and the device stability are both detrimental to the measurement when the sensing current is too high (Figure 3.1). Thus, lowering $\Delta V_{\text {noise }}$ is a more appropriate strategy to enhance the temperature resolution of suspended micro-thermometry technique. Contributions to the voltage noises are categorized as intrinsic noises (Johnson and shot noises) and non-intrinsic noises ( $1 / f$ noise, temperature drift, etc.). In this experiment, the total noise in the voltage signal can be estimated from

$\Delta V_{\text {noise }}^{2}=\Delta V_{\text {electrical }}^{2}+\Delta V_{\text {temperature drift }}^{2}$

where $\Delta V_{\text {electrical }}^{2}$ is the mean square of electrical noises arising from the intrinsic noises of resistance and the non-intrinsic nosie from the instrumentation, and $\Delta V_{\text {temperature drift }}^{2}$ is the measured mean square voltage noise due the ambient temperature drift of the sample mount. 


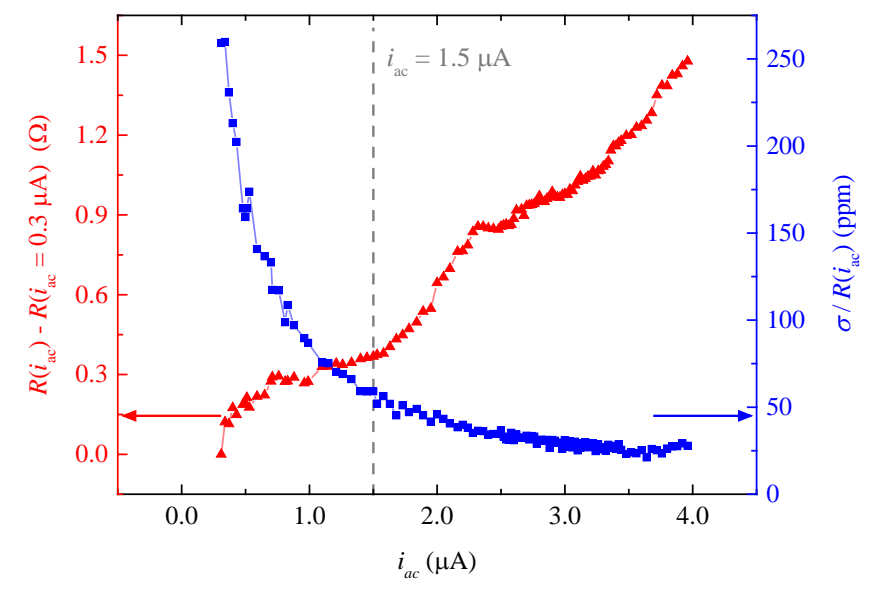

Figure 3.1. Rise in measured resistance of the PRT caused by self-heating from the AC sensing current, $\Delta R\left(i_{a c}\right)=R\left(i_{a c}\right)-R\left(i_{a c}=0.3 \mu A\right)$, as a function of $A C$ sensing current amplitude at 22.37 $H z$. The measured standard derivation of the resistance, $\sigma / R\left(i_{a c}\right)$, is shown for comparison in units of parts per million. An optimal $i_{a c}$ of $1.5 \mu \mathrm{A}$ peak-to-peak is used for the DC reversal technique based on minimizing noise while maintaining an acceptably small resistance rise corresponding to $71.6 \mathrm{mK}$.

A higher AC sensing current, $i_{\mathrm{ac}}$ is a separate strategy to lower the noise equivalent temperature as per Eq. 5, as well as the noise equivalent conductance, without contributing substantial modulated heating. I have measured the PRT resistance and its noise (ppm, $\left[\sigma / R\left(i_{\mathrm{ac}}\right)\right]^{*}$ $10^{6}$ ) as a function of sensing current from $0.3 \mu \mathrm{A}$ to $5 \mu \mathrm{A}$ (Figure 3.1). The electrical resistance of the PRT does not show a significant increase with a sensing current between $0.3-1.5 \mu \mathrm{A}$, indicating a negligible self-heating effect on the suspended membrane. In contrast, the standard derivation of measured resistance dramatically decreases with increasing $i_{\mathrm{ac}}$. In other words, the noises contributed from the electrical measurement can be minimized by applying a higher AC current, but this will also induce non-negligible self-heating. I calculated the temperature rise with $1.5 \mu \mathrm{A}$ AC current is $\sim 70 \mathrm{mK}$. Nevertheless, the rise of resistance due to AC current heating is a constant offset which will cancel out during the calculation of $\Delta R_{i}\left(I_{\mathrm{dc}}\right)=R_{i}\left(I_{\mathrm{dc}}\right)-R_{i}\left(I_{\mathrm{dc}}=0\right), i=\mathrm{h}$, s on each suspended membrane. To examine the effect of AC self-heating on the heat flow 
measurement, I have measured the temperature rise $\Delta T_{\mathrm{s}}$ on the sensing PRT as a function of DC heating power applied to the heating PRT from 0 to $3000 \mathrm{nW}$ with $0.5,1.5,2.5$, and $3.5 \mu \mathrm{A} \mathrm{AC}$ excitation current at $22.37 \mathrm{~Hz}$. The $\Delta T_{\mathrm{s}}$ measured with $1.5 \mu \mathrm{A}$ or higher AC excitation current offers three times better temperature resolution than $0.5 \mu \mathrm{A}$ and does not show a significant selfheating effect caused by the AC current. Device stability is also an important aspect during the measurement, thus $1.5 \mu \mathrm{A}$ has been chosen as the optimal AC excitation current to measure the $\mathrm{NET}_{\mathrm{s}}$ described subsequently as this current exhibits roughly the same temperature resolution as the higher currents shown in Figure 3.2.

I have measured the temperature rise $\Delta T_{\mathrm{s}}$ on the sensing PRT as a function of DC heating power applied to the heating PRT from 0 to $3000 \mathrm{nW}$ with 22.73, 12.95, and $2.97 \mu \mathrm{A}$ AC excitation frequency using $1.5 \mu \mathrm{A}$ AC excitation current. 1/f noise becomes the dominant noise as the frequency decreases. Thus I have chosen $22.37 \mathrm{~Hz}$ as the optimal AC excitation frequency to measure the $\mathrm{NET}_{\mathrm{s}}$ described subsequently as this frequency exhibits the best temperature resolution shown in Figure 3.3.

In order to determine $\mathrm{NET}_{\mathrm{s}}$, we need to identify the noise components of $\Delta V_{\text {noise. }}$ The major advantage of the DC reversal technique is that it can diminish $1 / f$ noises and noise due to offsets due to thermal drift. The common mode rejection ratio (CMRR) of an instrument describes the ability of common noise rejection in the measurement. The DC reversal system (Keithley 6221 and 2182A) has a CMRR of more than $200 \mathrm{~dB}\left(V_{\text {signal }} \pm V_{\text {noise }} / 10^{10}\right)$, this is extremely high in comparison to high-resolution lock-in amplifiers (Stanford Research Systems SR830) which only 


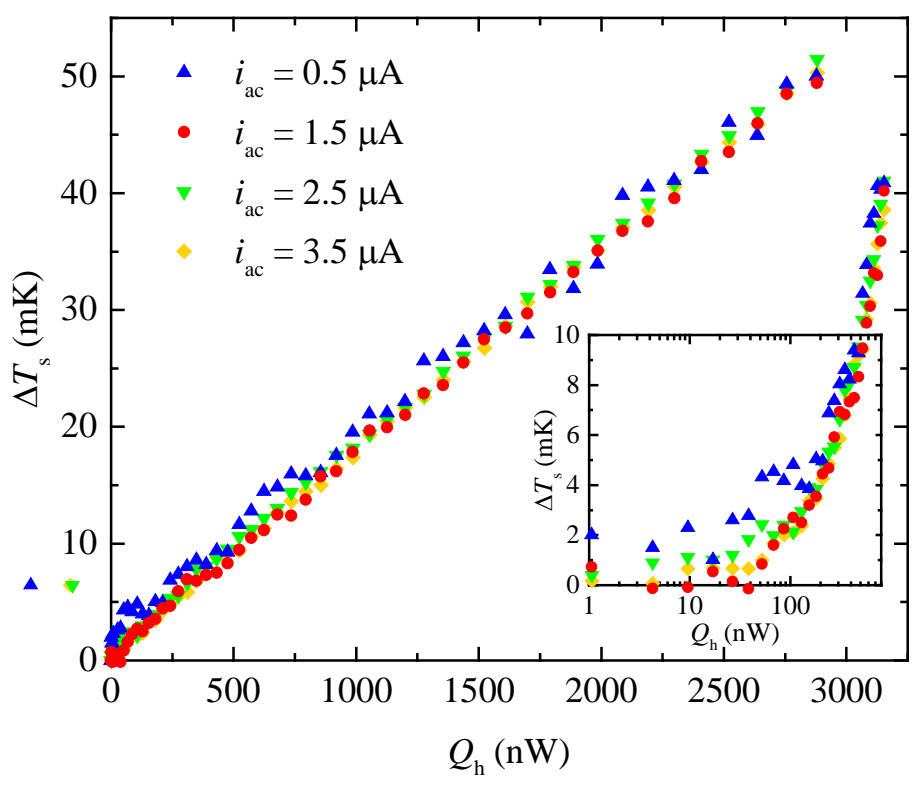

Figure 3.2. Measured sensing PRT temperature rise as a function of $Q_{h}=I_{d c}{ }^{2} R_{h}$, shown for varied AC excitation current $\left(f=22.37 \mathrm{~Hz}\right.$ ) of $0.5,1.5,2.5$, and $3.5 \mu \mathrm{A}$ and obtained at $T_{0}=375 \mathrm{~K}$. The inset shows the low $Q_{h}$ regime, note that $1.5 \mathrm{uA}$ is sufficient to achieve high resolution without inducing a large self-heating effect.

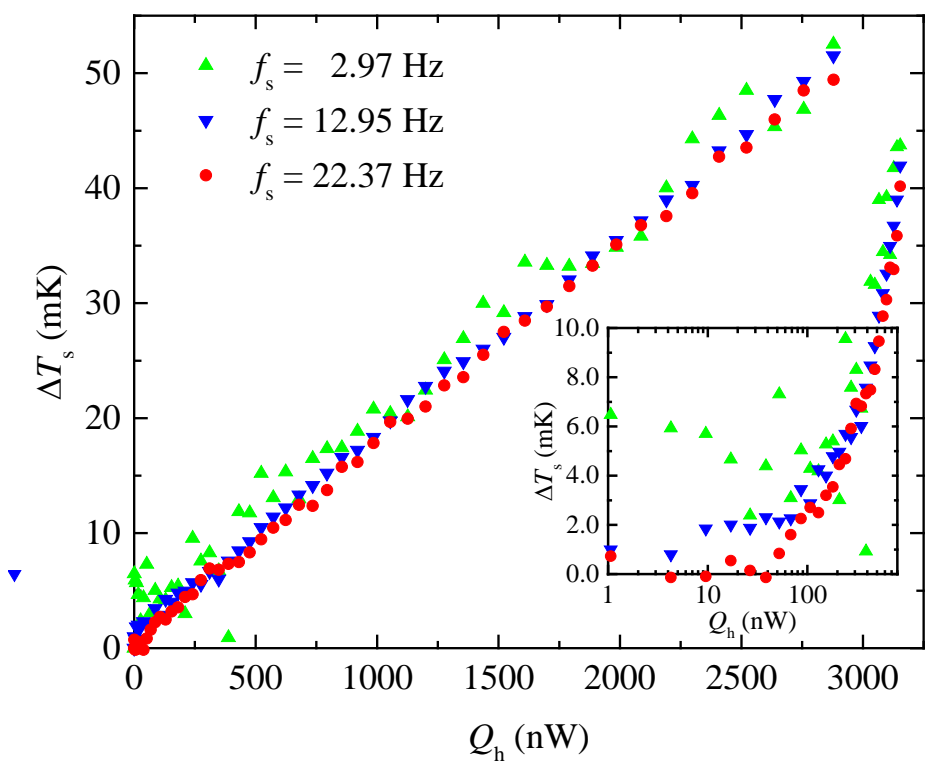

Figure 3.3. Measured sensing PRT temperature rise as a function of $Q_{h}=I_{d c}{ }^{2} R_{h}$, shown for varied AC excitation frequency of 22.37, 12.95, and $2.97 \mathrm{~Hz}\left(i_{a c}=1.5 \mu \mathrm{A}\right)$ and obtained at $T_{0}=375 \mathrm{~K}$. The inset shows the low $Q_{h}$ regime. Note that $22.97 \mathrm{~Hz}$ is the optimal frequency to achieve high temperature resolution, this is near the maximum frequency for the Delta mode $\left(f_{\max }=24 \mathrm{~Hz}\right.$, limited by instrumentation communication) and corresponds to the settings listed in Table 2.1. 
have a CMRR of $100 \mathrm{~dB}\left(V_{\text {signal }} \pm V_{\text {noise }} / 10^{5}\right)$. In other words, the instrumentation used in the DC reversal technique has a much better capability to reject non-intrinsic noises. In addition, the programmable current source used in this technique has an input impedance of $>10^{14} \Omega$ which is able to provide a stable and load-independent current through the PRTs $\left(\delta i_{\mathrm{ac}} / \mathrm{i}_{\mathrm{ac}} \sim 10^{-7}\right)$, effectively eliminating shot noise. Therefore, the Johnson noise is the only contribution to electrical noise and is expressed as

$$
\Delta V_{\text {electrical }}=\Delta V_{\text {Johnson }}=\left(4 k_{\mathrm{B}} T R \Delta f\right)^{0.5}
$$

and temperature drift $\Delta V_{\text {temperature drift }}$ are the major contributions to the $\Delta V_{\text {noise }}$ in the DC reversal measurement scheme used here. The noise equivalent bandwidth $\Delta f$ is $\sim 1 \mathrm{~Hz}$ for the DC reversal system. The NET Johnson at each ambient temperature point is calculated based on Eqs. 5 and 7. The $\mathrm{NET}_{\text {temperature drift }}$ represents the stability of the cryostat sample mount temperature and is directly obtained as the standard deviation of recorded sample mount temperatures during measurement. A summary of the temperature dependent contributions to NET is shown in Figure 3.4.

As I have obtained the $\mathrm{NET}_{\mathrm{s}}$ of the $\mathrm{DC}$ reversal technique, the noise equivalent conductance (NEG) of the suspended microdevice, which is the minimum thermal conductance that can be detected by the suspended device, can be expressed using Eqs. 2 and 5 as

$$
\mathrm{NEG}=G_{\mathrm{b}} \frac{\mathrm{NET}_{\mathrm{s}}}{\Delta T_{\mathrm{h}}-\Delta T_{\mathrm{s}}},
$$

where $G_{\mathrm{b}}$ is the measured thermal conductance of the six beams supporting each membrane. The $\mathrm{NET}_{\mathrm{s}}$ and NEG are calculated from the above analysis and shown in Table 3.1 for different sample mount temperatures. 


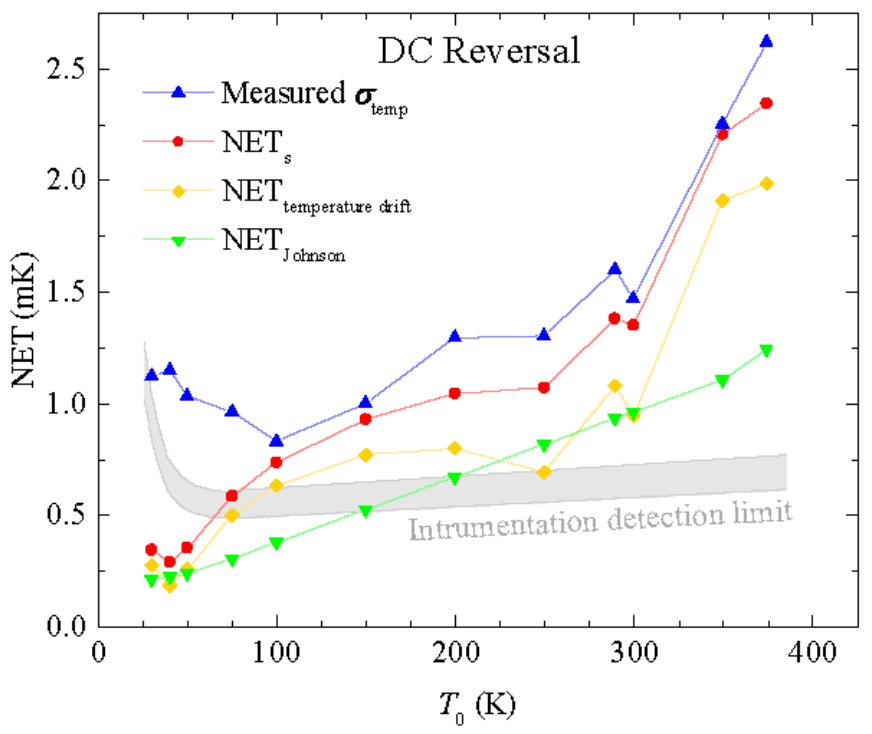

Figure 3.4. Temperature dependence of contributions to the sensing noise equivalent temperature $\left(N E T_{s}\right)$ of the DC reversal technique ( $N E T_{\text {temperature drift }}$ and $N E T_{\text {Johnson), shown in comparison to the }}$ total (pooled) standard deviation of the measured temperature rise, $\sigma_{\text {temp }}$, and the calculated delta mode instrumentation detection limit based on minimum resolution of $4.2-5 \mathrm{nV}$.

\subsection{Temperature resolution}

I have measured the background conductance on a blank device to experimentally determine the minimum temperature resolution and minimum thermal conductance resolution of the DC reversal suspended micro-thermometry technique over a temperature range of $1.0-2.6 \mathrm{~K}$ (Figure 3.5). During each measurement set, $I_{\mathrm{dc}}$ is applied to the heating membrane at discrete values from 0 to $+I_{\mathrm{dc}, \max }$ to $-I_{\mathrm{dc}, \max }$ and back to 0 . At each $I_{\mathrm{dc}}$ value, the average of 20 electrical resistance measurements of $\Delta R_{\mathrm{h}}\left(I_{\mathrm{dc}}\right)$ and the average of 200 measurements of $\Delta R_{\mathrm{s}}\left(I_{\mathrm{dc}}\right)$ are taken to determine $\Delta T_{\mathrm{h}}\left(I_{\mathrm{dc}}\right)$ and $\Delta T_{\mathrm{s}}\left(I_{\mathrm{dc}}\right)$ respectively. The difference in number of data points ensures both measurements end at roughly the same time, as $f_{\mathrm{h}}=3 \mathrm{~Hz}$ and $f_{\mathrm{s}}=22.37 \mathrm{~Hz}$. Figure 3.5 shows the measured temperature rise $\Delta T_{\mathrm{s}}$ on the sensing membrane as function of heating power $Q_{\mathrm{h}}$ at different sample mount temperatures. The standard derivation at each measured $\Delta T_{\mathrm{s}}$ is calculated 
(a)

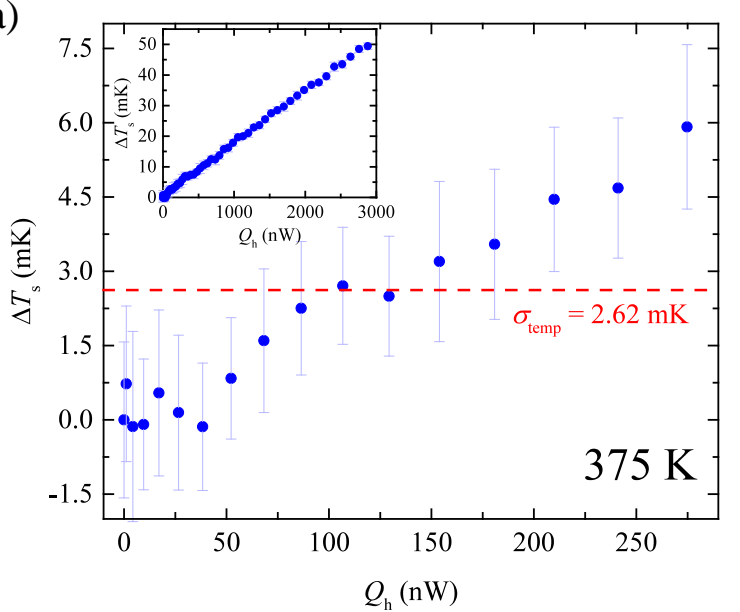

(c)

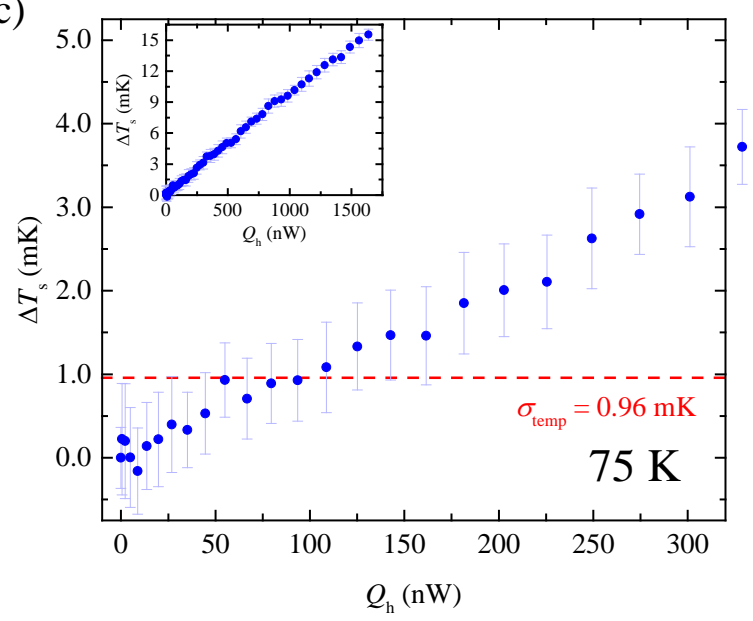

(b)

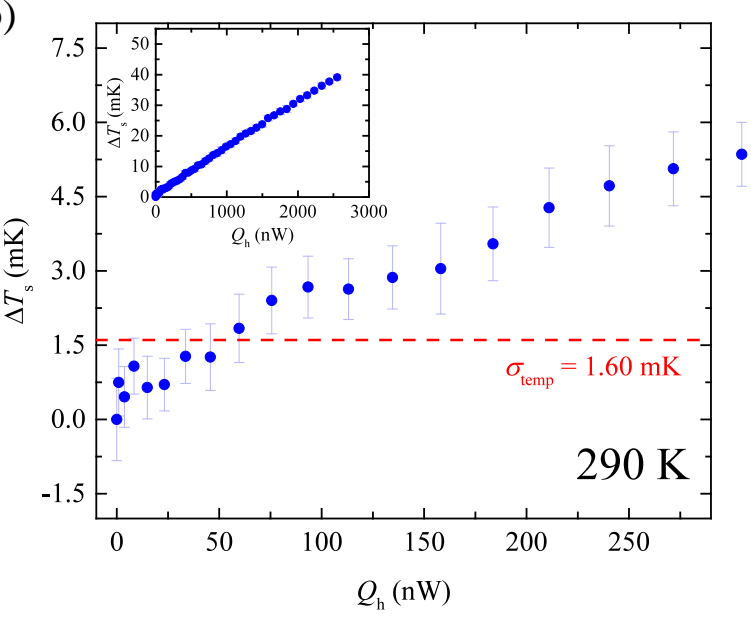

(d)

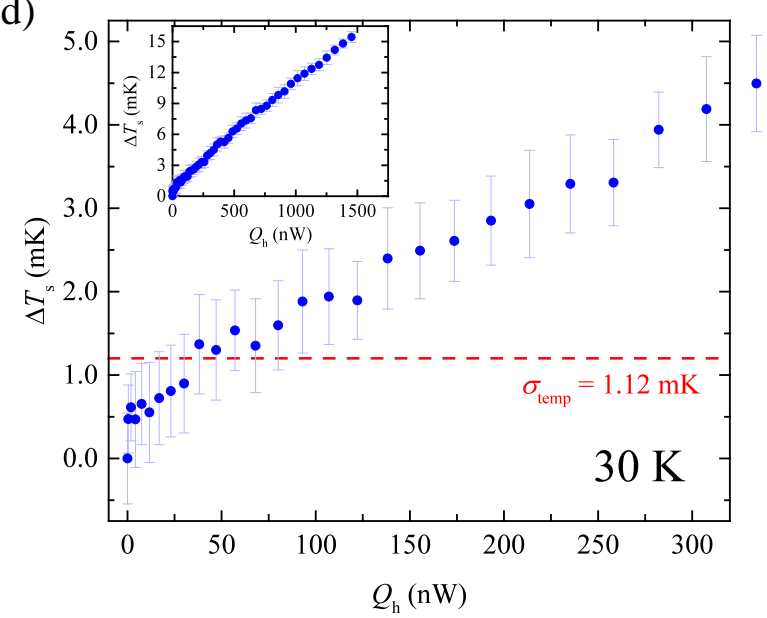

Figure 3.5. Measured temperature rise on the sensing $P R T, \Delta T_{s}$, as a function of heating power $Q_{h}$ detected using the DC reversal technique with a $1.5 \mu \mathrm{A} A C$ excitation current at $22.37 \mathrm{~Hz} . \mathrm{T}_{0}$ = (a) $375 \mathrm{~K}$, (b) $290 \mathrm{~K}$, (c) $75 \mathrm{~K}$, and (d) $30 \mathrm{~K}$. Error bars are defined as one standard deviation of $\Delta T_{s}\left(Q_{h}\right)$ over five separate measurement sets (one set is defined as $I_{d c}=0$ to $-I_{d c, \max }$ to $+I_{d c, \max }$ to 0). The measured total (pooled) standard deviation of the temperature rise, $\sigma_{\text {temp, }}$ is shown for comparison at each $T_{0}$.

based on five measurement sets at each heating power. In order to obtain statistics on the uncertainty of the entire measurement, the overall standard derivation of temperature rise, $\sigma_{\mathrm{temp}}$, is computed as a pooled standard deviation estimation from different populations ${ }^{43}$. The twenty 
measured $\Delta T_{\mathrm{s}}\left(Q_{\mathrm{h}}\right)$ at each heating power were considered as one statistical population (one set is defined as $I_{d c}=0$ to $-I_{d c, m a x}$ to $+I_{d c, m a x}$ to 0 ), the error bars in Figure 3.5 are defined to have a magnitude of one standard deviation of this population. As we used the same instruments throughout the whole experiment, the overall (pooled) standard derivation of the all the measured temperature rises was calculated as:

$\sigma_{\text {temp }}=\sqrt{\frac{\sum_{i=1}^{k}\left(\mathrm{n}_{i}-1\right) \sigma_{i}^{2}}{\sum_{i=1}^{k} \mathrm{n}_{i}-1}}$,

where $\sigma_{i}$ and $n_{i}$ are the sample standard derivation and sample size of the measured temperature rise at each heating power. The DC reversal method exhibits sensing temperature resolution, defined here as $\sigma_{\text {temp }}$, of $2.62 \mathrm{mK}, 1.60 \mathrm{mK}, 0.96 \mathrm{mK}$, and $1.12 \mathrm{mK}$ at ambient sample temperatures of $T_{0}=375 \mathrm{~K}, 290 \mathrm{~K}, 75 \mathrm{~K}$, and $30 \mathrm{~K}$ respectively. This is slightly higher than the $\mathrm{NET}_{\mathrm{s}}$ given in Table 3.1 and Figure 3.4. Thus, the temperature resolution is limited by the DC reversal measurement instrumentation which has a voltage resolution of $\sim 4.2-5 \mathrm{nV}$. This yields $\mathrm{NET}_{\text {instrumentation limit }}=0.65-0.74 \mathrm{mK}$. In other words, $0.65-0.74 \mathrm{mK}$ is the smallest temperature which the unmodified system can measure regardless of the $\mathrm{NET}_{\mathrm{s}}$. Impressively, the temperature resolution of this technique is able to achieve $1 \mathrm{mK}$ without using complicating schemes such as a matching resistance or Wheatstone bridge to cancel the temperature drift. This prevents the need for complicated calibration processes, multiple measurement schemes, and laborious data analysis and enables high-throughput measurement of the thermal conductance of individual nanostructures. 
Table 3.1. Summary of temperature and thermal conductance resolution for the DC reversal technique. The measured standard deviation of the sensing temperature rise, $\sigma_{\text {temp }}$, and the measured standard deviation of the background thermal conductance $\sigma_{G_{b g}}$ compare favorably with the NETs and NEG values.

\begin{tabular}{|c|c|c|c|c|c|c|}
\hline $\begin{array}{c}T_{\circ} \\
{[\mathrm{K}]}\end{array}$ & $\begin{array}{l}\text { NET Johnson }_{\text {on }} \\
{[\mathrm{mK}]}\end{array}$ & $\begin{array}{l}\mathrm{NET}_{\text {temperature drift }} \\
{[\mathrm{mK}]}\end{array}$ & $\begin{array}{c}\mathrm{NET}_{\mathrm{s}} \\
{\left[\mathrm{mK}^{\text {a) }}\right.}\end{array}$ & $\sigma_{\text {temp }}[\mathrm{mK}]$ & $\begin{array}{c}\text { NEG } \\
{[\mathrm{pW} / \mathrm{K}]^{\mathrm{b})}}\end{array}$ & $\sigma_{\mathrm{bg}}[\mathrm{pW} / \mathrm{K}]$ \\
\hline 375 & 1.24 & 1.99 & 2.35 & 2.62 & 22.75 & 26.42 \\
\hline 290 & 0.96 & 1.08 & 1.38 & 1.60 & 12.72 & 13.54 \\
\hline 75 & 0.31 & 0.49 & 0.58 & 0.96 & 3.42 & 6.16 \\
\hline 40 & 0.22 & 0.19 & 0.30 & 1.14 & 1.24 & 3.49 \\
\hline 30 & 0.21 & 0.29 & 0.36 & 1.12 & 1.21 & 1.73 \\
\hline
\end{tabular}

a) $\mathrm{NET}_{\mathrm{s}}^{2}=\mathrm{NET}_{\text {Johnson }}^{2}+\mathrm{NET}_{\text {temperature drift }}^{2}$

b) $\mathrm{NEG}=G_{\mathrm{b}} \cdot \mathrm{NET}_{\mathrm{s}} /\left(\Delta T_{\mathrm{h}}-\Delta T_{\mathrm{s}}\right)_{\max }$

I have also compared the DC reversal technique to the lock-in technique at $290 \mathrm{~K}$, as shown in Figure 3.6. The temperature resolution of the DC reversal technique is 5.9 times lower than the lock-in technique because the lock-in method has noise contribution from the voltage source of the amplifier, voltage to current converter, and short noises as well as the relatively poor CMNR of the SR830 in comparison to the DC reversal instrumentation. A reduced number of noise sources and improvement of the CMNR of the DC reversal system allow us to achieve this improvement in resolution. The $\mathrm{NET}_{\mathrm{s}}$ can be further improved if a matching resistance or Wheatstone Bridge is used to cancel the temperature drift with differential amplifiers that have same order of CMNR as the current system. But the matching resistance, Wheatstone bridge, or the differential amplifiers would contribute non-intrinsic noises to the measurement system as well as increase the experimental complexity by requiring each measurement to be calibrated and hence would void the high-throughput nature of our technique. 


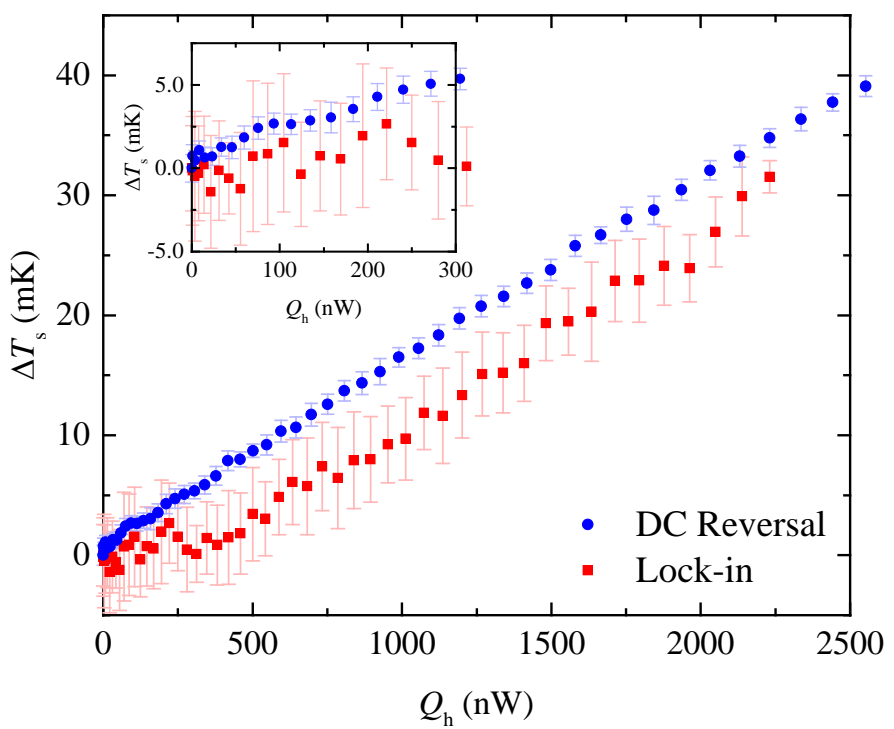

Figure 3.6. Measured sensing $P R T$ temperature rise $\Delta T_{s}$ as a function of heating power $Q_{h}$ at 290 $K$. The DC reversal technique is measured with $1.5 \mu \mathrm{A} A C$ excitation current at $22.37 \mathrm{~Hz}$. The lock-in technique is measured with $1.5 \mu$ A (peak-to-peak) AC excitation current at $199.03 \mathrm{~Hz}$ using a $1 \mathrm{M} \Omega$ precision resistor to convert the lock-in amplifier internal voltage source to a current source. The total (pooled) uncertainty of $\Delta T_{s}$, defined as $\sigma_{\text {temp, }}$, measured by the lock-in method is $9.38 \mathrm{mK}$ while that of DC reversal technique is an order of magnitude lower at $1.59 \mathrm{mK}$.

\subsection{Thermal conductance resolution}

The resolution of thermal conductance is also substantially improved in this work. Based on five measurement sets at ambient sample temperature $T_{0}=375 \mathrm{~K}, 290 \mathrm{~K}, 75 \mathrm{~K}$, and $30 \mathrm{~K}$, the measured thermal background conductance $G_{\mathrm{bg}}$ is $548.75 \mathrm{pW} / \mathrm{K}, 347.46 \mathrm{pW} / \mathrm{K}, 91.45 \mathrm{pW} / \mathrm{K}$, and $46.41 \mathrm{pW} / \mathrm{K}$ and the standard derivation of $G_{\mathrm{bg}}$ is $26.42 \mathrm{pW} / \mathrm{K}, 13.54 \mathrm{pW} / \mathrm{K}, 6.16 \mathrm{pW} / \mathrm{K}$, and 1.73 $\mathrm{pW} / \mathrm{K}$ respectively. As standard deviation of the measurement is on the order of NEG, I have confidence that I have reached the instrumentation limitation of this technique. The $G_{\mathrm{b}}$ and $G_{\mathrm{bg}}$ measured at different average temperature, $T_{\text {avg }}=T_{0}+1 / 2 T_{\max }$ where $T_{\max }$ is the maximum temperature rise by the DC current on the heating membrane, is shown in Figure 3.8. The $\delta G_{\mathrm{b}} / G_{\mathrm{b}}$ and $\delta G_{\mathrm{bg}} / G_{\mathrm{bg}}$ are better than $2.2 \%$ and $4.5 \%$ respectively and $G_{\mathrm{b}}$ and $G_{\mathrm{bg}}$ were able to be measured 
without a significant heating on the heating membrane. The DC reversal technique has a significant improvement on measuring thermal conductance over the lock-in technique (Figure 3.8).

Additionally, in comparison with $G_{b}$ measured by the DC reversal technique, where $\zeta=3$ in Eq. 4, the $G_{\mathrm{b}}$ measured at $290 \mathrm{~K}$ by the lock-in method is $\sim 5 \%$ lower (Figure 3.7). This is a significant unreported uncertainty of the lock-in technique, where at high frequencies $\zeta \neq 1$ (see Figures 2.5-2.7) as is commonly assumed. An additional complication is that the actual value of $\zeta$ is a function of temperature in the high frequency regime as shown in Figure 2.7. Assuming $\Delta T_{\mathrm{h}}$ $>\Delta T_{\mathrm{s}}$, this leads to an overestimation of $\Delta T_{\mathrm{h}}$ by a factor of $1 / \zeta$ according to Eq. 4 and a corresponding underestimation in $G_{\mathrm{b}}$ by a factor of $\zeta$. Similarly, $G_{\mathrm{b}} / G_{\mathrm{s}}$ is underestimated by a factor of $\zeta$ based on Eq. 2, and the calculated $G_{\mathrm{s}}$ is then underestimated by a factor of $\zeta^{2}$. At 290 $\mathrm{K}$, I have measured $\zeta(f=747.7 \mathrm{~Hz})=1.043$ and a corresponding underestimation of $G_{\mathrm{b}}$ by $4.4 \%$ compared to the DC reversal technique, in good agreement with the $4.3 \%$ underestimation predicted based on the measured value of $\zeta$. This problem is remedied using the DC reversal technique which is stable at very low frequencies where the value of $\zeta$ is uniquely 3. 
(a)

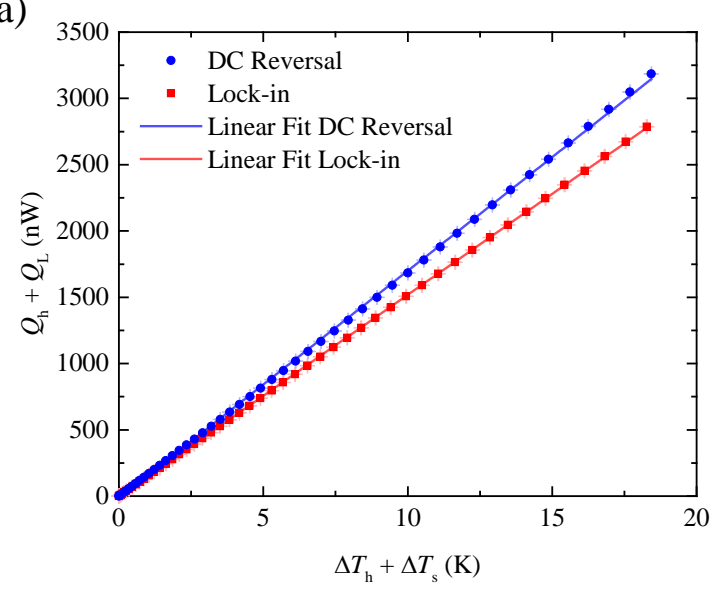

(b)

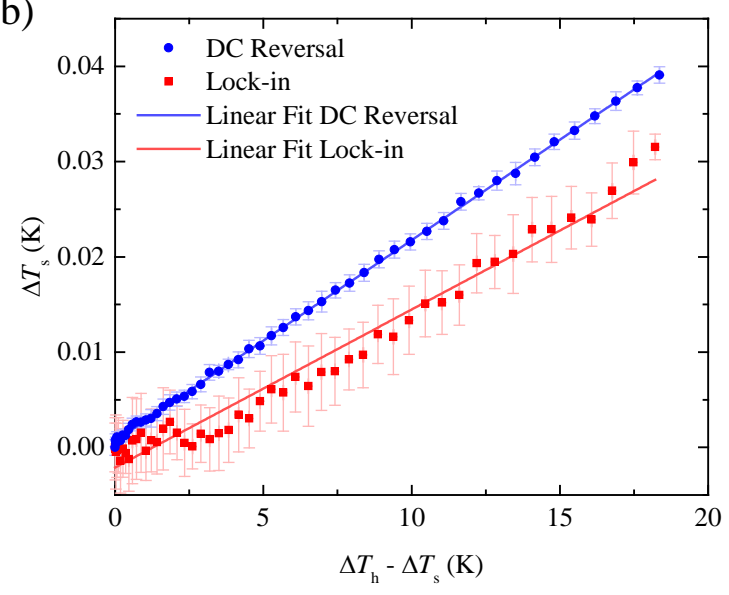

Figure 3.7. (a) Total heat conducted through the six beams supporting the heating membrane to the environment, the the slope of $Q_{h}+Q_{L}$ as a function of $\Delta T_{h}+\Delta T_{s}$ yields $G_{b}$. (b) Corresponding temperature rise on the sensing membrane, $\Delta T_{s}$ as a function of $\Delta T_{h}-\Delta T_{s}$, the slope yields the ratio of $G_{b} / G_{s}$.

(a)

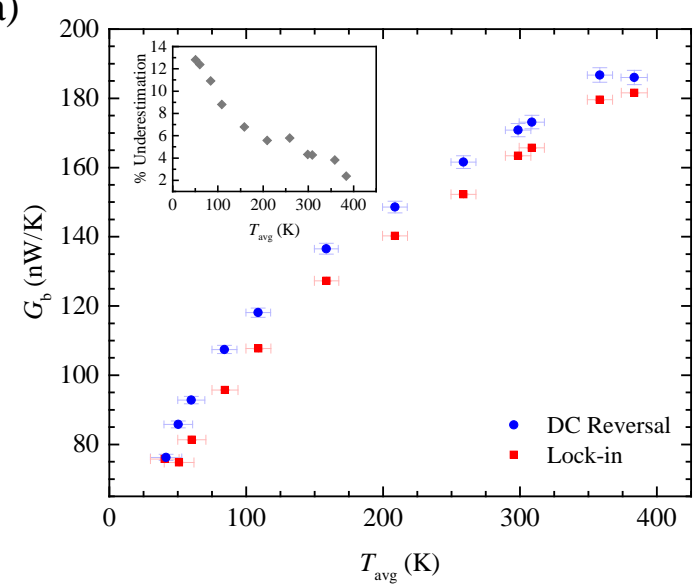

(b)

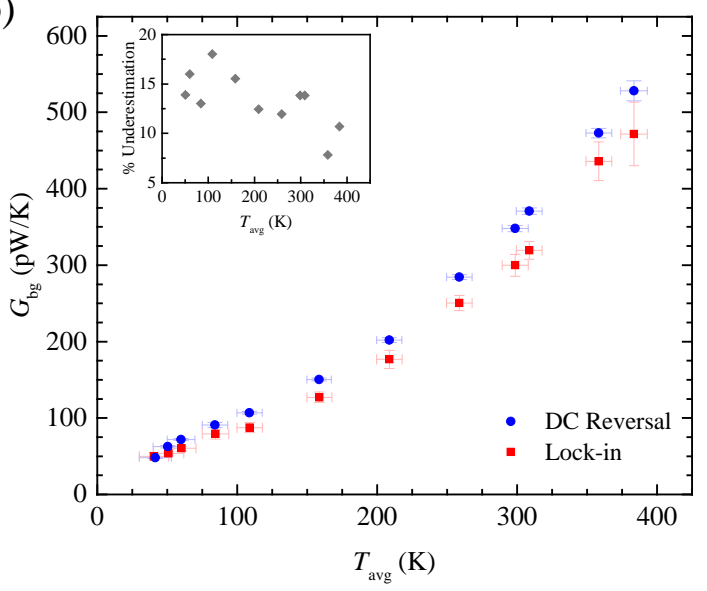

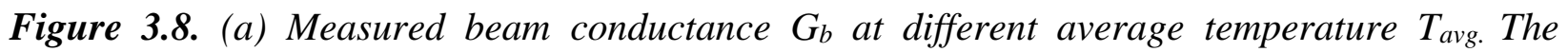
uncertainty of $G_{b}$ is better than $2.2 \%$ within a $20 \mathrm{~K}$ temperature range. (b) Measured background conductance $G_{b g}$ at different average temperature $T_{a v g .}$. The uncertainty of $G_{b g}$ is on the order of 2.47 - $6.75 \%$ within a $20 \mathrm{~K}$ temperature range. This is an impressive improvement from the traditional lock-in-based technique which exhibits uncertainty of $\sim 9.35-86 \%$ and requires a much higher temperature rise of $50 \mathrm{~K}$ at $T_{0}=77 \mathrm{~K}$. The lock-in data is reproduced from Ref. 44, which uses a voltage source and high-value resistor to generate DC heating current. The red square indicates $G_{b g}$ measured with lock-in technique in this work by employing a DC current source and using two times higher AC sensing current than Ref. 44. The uncertainty of $G_{b g}$ is $9.2 \%$ within a 20 K temperature range and while it showed certain improvement from previous work but it is not as good as DC reversal technique. 


\section{Chapter 4 - Conclusion}

In summary, we have developed a new resistance thermometry measurement scheme benefitting from improved common mode noise rejection over traditional lock-in amplifier-based techniques. This DC reversal technique offers a high throughput and simple measurement scheme with $\sim 1.6 \mathrm{mK}$ temperature resolution and $\sim 14 \mathrm{pW} / \mathrm{K}$ thermal conductance resolution at $290 \mathrm{~K}$. Additionally, the DC reversal technique removes offset and low frequency noises and exhibits less than one half the amount of white noise and an order of magnitude lower $1 / f$ noise than commonly used lock-in amplifiers. Given these results, the DC reversal technique combined with suspended micro-thermometry will enable fundamental studies of phonon transport at the molecular scale where both high throughput and high resolution are required. 


\section{References}

[1] J. Hone, B. Batlogg, Z. Benes, A. T. Johnson, and J. E. Fischer, "Quantized phonon spectrum of single-wall carbon nanotubes," Science 289, 1730 (2000). http://dx.doi.org/10.1126/science.289.5485.1730

[2] P. Kim, L. Shi, A. Majumdar, and P. L. McEuen, "Thermal transport measurements of individual multiwalled nanotubes," Phys. Rev. B 87, 215502 (2001). http://dx.doi.org/10.1103/PhysRevLett.87.215502

[3] L. Shi, D. Li, C. Yu, W. Jang, D. Kim, Z. Yao, P. Kim, and A. Majumdar, "Measuring thermal and thermoelectric properties of one-dimensional nanostructures using a microfabricated device," J. Heat Transfer 125, 881 (2003). http://dx.doi.org/10.1115/1.1597619

[4] E. Pop, D. Mann, Q. Wang, K. Goodson, and H. Dai, "Thermal conductance of an individual single-wall carbon nanotube above room temperature," Nano Lett. 6, 96 (2006). http://dx.doi.org/10.1021/nl052145f

[5] I.-K. Hsu, R. Kumar, A. Bushmaker, S. B. Cronin, M. T. Pettes, L. Shi, T. Brintlinger, M. S. Fuhrer, and J. Cumings, "Optical measurement of thermal transport in suspended carbon nanotubes," Appl. Phys. Lett. 92, 063119 (2008).

http://dx.doi.org/10.1063/1.2829864

[6] I.-K. Hsu, M. T. Pettes, M. Aykol, C.-C. Chang, W.-H. Hung, J. Theiss, L. Shi, and S. B. Cronin, "Direct observation of heat dissipation in individual suspended carbon nanotubes using a two-laser technique," J. Appl. Phys. 110, 044328 (2011). http://dx.doi.org/10.1063/1.3627236

[7] D. Li, Y. Wu, P. Kim, L. Shi, P. Yang, and A. Majumdar, "Thermal conductivity of individual silicon nanowires," Appl. Phys. Lett. 83, 2934 (2003). http://dx.doi.org/10.1063/1.1616981

[8] J. Zhou, C. Jin, J. H. Seol, X. Li, and L. Shi, "Thermoelectric properties of individual electrodeposited bismuth telluride nanowires," Appl. Phys. Lett. 87, 133109 (2005). http://dx.doi.org/10.1063/1.2058217

[9] A. Boukai, K. Xu, and J. R. Heath, "Size-dependent transport and thermoelectric properties of individual polycrystalline bismuth nanowires," Adv. Mater. 18, 864 (2006). http://dx.doi.org/10.1002/adma.200502194

[10] A. L. Moore, M. T. Pettes, F. Zhou, and L. Shi, "Thermal conductivity suppression in bismuth nanowires," J. Appl. Phys. 106, 034310 (2009). http://dx.doi.org/10.1063/1.3191657 
[11] A. Mavrokefalos, A. L. Moore, M. T. Pettes, L. Shi, W. Wang, and X. Li, "Thermoelectric and structural characterizations of individual electrodeposited bismuth telluride nanowires," J. Appl. Phys. 105, 104318 (2009). http://dx.doi.org/10.1063/1.3133145

[12] J. Kim, S. Lee, Y. M. Brovman, P. Kim, and W. Lee, "Diameter-dependent thermoelectric figure of merit in single-crystalline Bi nanowires," Nanoscale 7, 5053 (2015). http://dx.doi.org/10.1039/C4NR06412G

[13] S. Shen, A. Henry, J. Tong, R. Zheng, and G. Chen, "Polyethylene nanofibres with very high thermal conductivities," Nat. Nanotechnol. 5, 251 (2010). http://dx.doi.org/10.1038/nnano.2010.27

[14] V. Singh, T. L. Bougher, A. Weathers, Y. Cai, K. Bi, M. T. Pettes, S. A. McMenamin, W. Lv, D. P. Resler, T. R. Gattuso, D. H. Altman, K. H. Sandhage, L. Shi, A. Henry, and B. A. Cola, "High thermal conductivity of chain-oriented amorphous polythiophene," Nat. Nanotechnol. 9, 384 (2014). http://dx.doi.org/10.1038/nnano.2014.44

[15] A. Weathers, Z. U. Khan, R. Brooke, D. Evans, M. T. Pettes, J. W. Andreasen, X. Crispin, and L. Shi, "Significant electronic thermal transport in the conducting polymer poly(3,4-ethylenedioxythiophene)," Adv. Mater. 27, 2101 (2015). http://dx.doi.org/10.1002/adma.201404738

[16] C. Chiritescu, D. G. Cahill, N. Nguyen, D. Johnson, A. Bodapati, P. Keblinski, and P. Zschack, "Ultralow thermal conductivity in disordered, layered WSe2 crystals," Science 315, 351 (2007). http://dx.doi.org/10.1126/science.1136494

[17] A. Mavrokefalos, Q. Lin, M. Beekman, J. H. Seol, Y. J. Lee, H. Kong, M. T. Pettes, D. C. Johnson, and L. Shi, "In-plane thermal and thermoelectric properties of misfit-layered $\left[(\mathrm{PbSe})_{0.99}\right]_{x}\left(\mathrm{WSe}_{2}\right)_{x}$ superlattice thin films," Appl. Phys. Lett. 96 (2010). http://dx.doi.org//10.1063/1.3428577

[18] A. A. Balandin, S. Ghosh, W. Bao, I. Calizo, D. Teweldebrhan, F. Miao, and C. N. Lau, "Superior thermal conductivity of single-layer graphene," Nano Lett. 8, 902 (2008). http://dx.doi.org/10.1021/nl0731872

[19] J. H. Seol, I. Jo, A. L. Moore, L. Lindsay, Z. H. Aitken, M. T. Pettes, X. Li, Z. Yao, R. Huang, D. Broido, N. Mingo, R. S. Ruoff, and L. Shi, "Two-dimensional phonon transport in supported graphene," Science 328, 213 (2010). http://dx.doi.org/10.1126/science.1184014

[20] R. Yan, J. R. Simpson, S. Bertolazzi, J. Brivio, M. Watson, X. Wu, A. Kis, T. Luo, A. R. Hight Walker, and H. G. Xing, "Thermal conductivity of monolayer molybdenum disulfide obtained from temperature-dependent raman spectroscopy," ACS Nano 8, 986 (2014). http://dx.doi.org/10.1021/nn405826k 
[21] I. Jo, M. T. Pettes, E. Ou, W. Wu, and L. Shi, "Basal-plane thermal conductivity of fewlayer molybdenum disulfide," Appl. Phys. Lett. 104, 201902 (2014).

http://dx.doi.org/10.1063/1.4876965

[22] I. Jo, M. T. Pettes, J. Kim, K. Watanabe, T. Taniguchi, Z. Yao, and L. Shi, "Thermal conductivity and phonon transport in suspended few-layer hexagonal boron nitride," Nano Lett. 13, 550 (2013). http://dx.doi.org/10.1021/nl304060g

[23] J. Yang, Y. Yang, S. W. Waltermire, X. Wu, H. Zhang, T. Gutu, Y. Jiang, Y. Chen, A. A. Zinn, R. Prasher, T. T. Xu, and D. Li, "Enhanced and switchable nanoscale thermal conduction due to van der Waals interfaces," Nat. Nanotechnol. 7, 91 (2012). http://dx.doi.org/10.1038/nnano.2011.216

[24] Z. Wang, R. Xie, C. T. Bui, D. Liu, X. Ni, B. Li, and J. T. L. Thong, "Thermal transport in suspended and supported few-layer graphene," Namo Lett. 11, 113 (2011). http://dx.doi.org/10.1021/nl102923q

[25] G. Chen and A. Shakouri, "Heat transfer in nanostructures for solid-state energy conversion," J. Heat Transfer 124, 242 (2001). http://dx.doi.org/10.1115/1.1448331

[26] M. F. L. De Volder, S. H. Tawfick, R. H. Baughman, and A. J. Hart, "Carbon nanotubes: present and future commercial applications," Science 339, 535 (2013). http://dx.doi.org/10.1126/science.1222453

[27] L. Shi, C. Dames, J. R. Lukes, P. Reddy, J. Duda, D. G. Cahill, J. Lee, A. Marconnet, K. E. Goodson, J.-H. Bahk, A. Shakouri, R. S. Prasher, J. Felts, W. P. King, B. Han, and J. C. Bischof, "Evaluating broader impacts of nanoscale thermal transport research," Nanosc. Microsc. Therm. 19, 127 (2015). http://dx.doi.org/10.1080/15567265.2015.1031857

[28] A. A. Balandin, "Thermal properties of graphene and nanostructured carbon materials," Nat. Mater. 10, 569 (2011). http://dx.doi.org/10.1038/nmat3064

[29] S. Z. Butler, S. M. Hollen, L. Cao, Y. Cui, J. A. Gupta, H. R. Gutiérrez, T. F. Heinz, S. S. Hong, J. Huang, A. F. Ismach, E. Johnston-Halperin, M. Kuno, V. V. Plashnitsa, R. D. Robinson, R. S. Ruoff, S. Salahuddin, J. Shan, L. Shi, M. G. Spencer, M. Terrones, W. Windl, and J. E. Goldberger, "Progress, challenges, and oportunities in two-dimensional materials beyond graphene," ACS Nano 7, 2898 (2013). http://dx.doi.org/10.1021/nn400280c

[30] S. Chen, Q. Wu, C. Mishra, J. Kang, H. Zhang, K. Cho, W. Cai, A. A. Balandin, and R. S. Ruoff, "Thermal conductivity of isotopically modified graphene," Nat. Mater. 11, 203 (2012). http://dx.doi.org/10.1038/nmat3207

[31] K. E. Goodson and Y. S. Ju, "Heat conduction in novel electronic films," Annu. Rev. Mater. Sci. 29, 261 (1999). http://dx.doi.org/10.1146/annurev.matsci.29.1.261 
[32] T. Kodama, A. Jain, and K. E. Goodson, "Heat conduction through a DNA-gold composite," Nano Lett. 9, 2005 (2009). http://dx.doi.org/10.1021/nl900272m

[33] M. T. Pettes, H. Ji, R. S. Ruoff, and L. Shi, "Thermal transport in three-dimensional foam architectures of few-layer graphene and ultrathin graphite," Nano Lett. 12, 2959 (2012). http://dx.doi.org/10.1021/nl300662q

[34] A. K. Vallabhaneni, D. Singh, H. Bao, J. Murthy, and X. Ruan, "Reliability of raman measurements of thermal conductivity of single-layer graphene due to selective electronphonon coupling: a first-principles study," Phys. Rev. B 93, 125432 (2016). http://dx.doi.org/10.1103/PhysRevB.93.125432

[35] V. V. Deshpande, S. Hsieh, A. W. Bushmaker, M. Bockrath, and S. B. Cronin, "Spatially resolved temperature measurements of electrically heated carbon nanotubes," Phys. Rev. Lett. 102, 105501 (2009). http://dx.doi.org/10.1103/PhysRevLett.102.105501

[36] A. Weathers, K. Bi, M. T. Pettes, and L. Shi, "Reexamination of thermal transport measurements of a low-thermal conductance nanowire with a suspended micro-device," Rev. Sci. Instrum. 84, 084903 (2013). http://dx.doi.org/10.1063/1.4816647

[37] S. Sadat, E. Meyhofer, and P. Reddy, "Resistance thermometry-based picowatt-resolution heat-flow calorimeter," Appl. Phys. Lett. 102, 163110 (2013).

http://dx.doi.org/10.1063/1.4802239

[38] J. Zheng, M. C. Wingert, E. Dechaumphai, and R. Chen, "Sub-picowatt/kelvin resistive thermometry for probing nanoscale thermal transport," Rev. Sci. Instrum. 84, 114901 (2013). http://dx.doi.org/doi:http://dx.doi.org/10.1063/1.4826493

[39] S. Sadat, E. Meyhofer, and P. Reddy, "High resolution resistive thermometry for micro/nanoscale measurements," Rev. Sci. Instrum. 83, 084902 (2012). http://dx.doi.org/10.1063/1.4744963

[40] A. Daire, W. Goeke, and M. A. Tupta, "New Instruments Can Lock Out Lock-ins," Keithley Instruments, Inc. http://www.tek.com/sites/tek.com/files/media/document/resources/Lock-In\%20WP.pdf

[41] M. T. Pettes and L. Shi, "Thermal and structural characterizations of individual single-, double-, and multi-walled carbon nanotubes," Adv. Funct. Mater. 19, 3918 (2009). http://dx.doi.org/10.1002/adfm.200900932

[42] A. L. Moore and L. Shi, "On errors in thermal conductivity measurements of suspended and supported nanowires using micro-thermometer devices from low to high temperatures," Meas. Sci. Technol. 22, 015103 (2011). http://dx.doi.org/10.1088/0957$\underline{0233 / 22 / 1 / 015103}$

[43] R. M. Bethea, Statistical Methods for Engineers and Scientists (CRC Press, Boca Raton, FL, 1995), p. 672. ISBN 9780824793357. https://www.crcpress.com/Statistical-Methodsfor-Engineers-and-Scientists-Third-Edition/Bethea/9780824793357 
[44] M. T. Pettes, I. Jo, Z. Yao, and L. Shi, "Influence of polymeric residue on the thermal conductivity of suspended bilayer graphene," Nano Lett. 11, 1195 (2011).

http://dx.doi.org/10.1021/nl104156y 